\title{
NOx Control Options and Integration for US Coal Fired Boilers
}

\section{Quarterly Progress Report}

\author{
Reporting Period Start Date October 1, 2001
}

Reporting Period End Date: December 31, 2001

\author{
Mike Bockelie, REI \\ Marc Cremer, REI \\ Kevin Davis, REI \\ Connie Senior, REI \\ Bob Hurt and Eric Suuberg, Brown University \\ Eric Eddings, University of Utah \\ Larry Baxter, Brigham Young University
}

January 31,2002

DOE Cooperative Agreement No: DE-FC26-00NT40753

Reaction Engineering International

77 West 200 South, Suite 210

Salt Lake City, UT 84101 


\section{Disclaimer}

"This report was prepared as an account of work sponsored by an agency of the United States Government. Neither the United States Government nor any agency thereof, nor any of their employees, makes any warranty, express or implied, or assumes any legal liability or responsibility for the accuracy, completeness, or usefulness of any information, apparatus, product, or process disclosed, or represents that its use would not infringe privately owned rights. Reference herein to any specific commercial product, process, or service by trade name, trademark, manufacturer, or otherwise does not necessarily constitute or imply its endorsement, recommendation, or favoring by the United States Government or any agency thereof. The views and opinions of authors expressed herein do not necessarily state or reflect those of the United States Government or any agency thereof." 


\begin{abstract}
This is the sixth Quarterly Technical Report for DOE Cooperative Agreement No: DE-FC2600NT40753. The goal of the project is to develop cost effective analysis tools and techniques for demonstrating and evaluating low NOx control strategies and their possible impact on boiler performance for firing US coals. The Electric Power Research Institute (EPRI) is providing cofunding for this program. This program contains multiple tasks and good progress is being made on all fronts. Preliminary results from laboratory and field tests of a corrosion probe to predict waterwall wastage indicate good agreement between the electrochemical noise corrosion rates predicted by the probe and corrosion rates measured by a surface profilometer. Four commercial manufacturers agreed to provide catalyst samples to the program. BYU has prepared two V/Ti oxide catalysts (custom, powder form) containing commercially relevant concentrations of $\mathrm{V}$ oxide and one containing a W oxide promoter. Two pieces of experimental apparatus being built at BYU to carry out laboratory-scale investigations of SCR catalyst deactivation are nearly completed. A decision was made to carry out the testing at full-scale power plants using a slipstream of gas instead of at the University of Utah pilot-scale coal combustor as originally planned. Design of the multi-catalyst slipstream reactor was completed during this quarter. One utility has expressed interest in hosting a long-term test at one of their plants that co-fire wood with coal. Tests to study ammonia adsorption onto fly ash have clearly established that the only routes that can play a role in binding significant amounts of ammonia to the ash surface, under practical ammonia slip conditions, are those that must involve co-adsorbates.
\end{abstract}




\section{Table of Contents}

DISCLAIMER

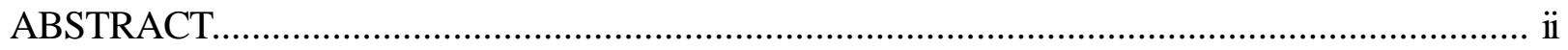

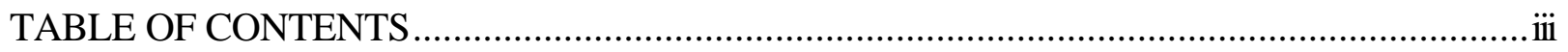

EXECUTIVE SUMMARY ................................................................................ 1

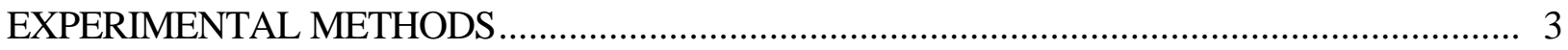

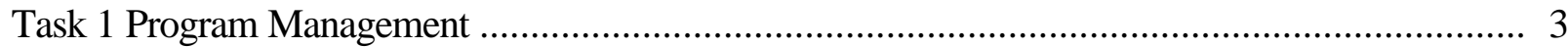

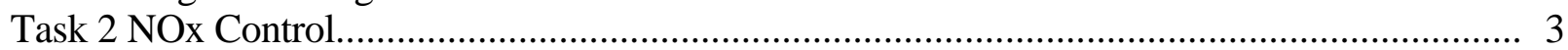

Task 3 Minimization of Impacts .................................................................................... 4

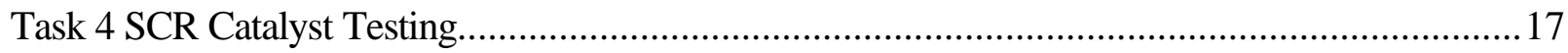

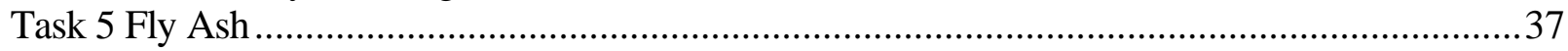

Task 6 Field Validation of Integrated Systems................................................................4

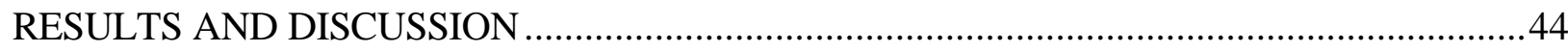

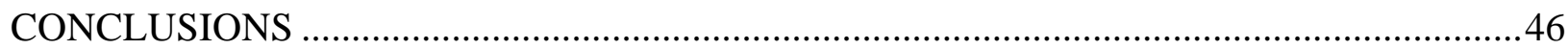

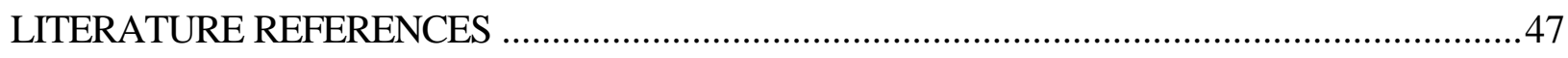

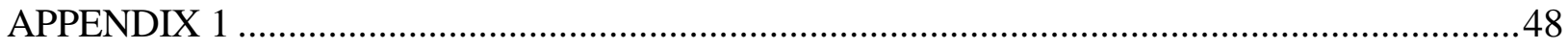




\section{Executive Summary}

The work to be conducted in this project received funding from the Department of Energy under Cooperative Agreement No: DE-FC26-00NT40753. This project has a period of performance that started February 14, 2000 and continues through September 30, 2002.

Our program contains five major technical tasks:

- evaluation of Rich Reagent Injection (RRI) for in-furnace NOx control

- demonstration of RRI technologies in utility boiler scale field tests

- impacts of combustion modifications (including corrosion and soot)

- ammonia adsorption / removal from fly ash

- $\quad$ SCR catalyst testing

To date good progress is being made on the overall program. We have seen considerable interest from industry in the program due to our initial successful field tests of the RRI technology and the corrosion monitor.

During the last three months, our accomplishments include the following:

$>$ Completed licensing agreements with the Electric Power Research Institute (EPRI) and Fuel Tech, Inc. for Rich Reagent Injection (RRI) technology.

$>$ Completed laboratory tests to evaluate predictive capability of a corrosion probe under controlled conditions. Further work on analysis of the data for field tests performed at Eastlake Power Station has been performed. Preliminary results indicate good agreement between the electrochemical noise corrosion rates predicted by the probe and corrosion rates measured by a surface profilometer as part of the field and laboratory tests.

$>$ Four commercial manufacturers of SCR catalysts have agreed to provide samples to the program. BYU has prepared two V/Ti oxide catalysts (custom, powder form) containing commercially relevant concentrations of $\mathrm{V}$ oxide and one containing a $\mathrm{W}$ oxide promoter. This makes for a total of six SCR catalysts that will be tested under Task 4, four monolith and two plate. Confidentiality Agreements were completed with all the catalyst vendors to allow them provide samples.

$>$ Two pieces of experimental apparatus being built at BYU to carry out laboratory-scale investigations of SCR catalyst deactivation are near completion: the kinetic flow reactor (KSR) and the in-situ spectroscopy reactor (ISR). Experiments in the KSR will focus on obtaining the kinetic coefficients and mechanistic information. Deactivation will be determined by measuring specific intrinsic activity of custom and commercial catalysts impregnated to different contaminant levels. The first gas flow through the reactor is scheduled for end of January. The ISR is designed to quantify species adsorbed on surfaces during reaction and provide quantitative indication of acidity and active site mechanisms. Construction of the ISR is nominally complete and initial data have been collected.

$>$ A decision was made to conduct catalyst testing at full-scale power plants using a slipstream of gas instead of at the University of Utah pilot-scale coal combustor as originally planned. Design of the multi-catalyst slipstream reactor was completed by the University of Utah 
during this quarter. One utility has expressed interest in hosting a long-term test at one of their plants that co-fires wood with coal. A contract modification has been requested from DOE.

$>$ A series of tests for ammonia adsorption onto fly ash have been concluded that clearly establish that the only routes that can play a role in binding significant amounts of ammonia to the ash surface, under practical ammonia slip conditions, are those that must involve coadsorbates. The role of $\mathrm{SO}_{2}$ has been hypothesized to be particularly significant. 


\section{Experimental Methods}

Within this section we present in order, brief discussions on the different tasks that are contained within this program. For simplicity, the discussion items are presented in the order of the Tasks as outlined in our original proposal.

\section{Task 1 - Program Management}

Licensing agreements for Rich Reagent Injection (RRI) have been completed with two organizations. RRI was originally co-developed by EPRI and REI. Through this DOE program field tests of RRI in cyclone fired utility boilers have been performed that have generated sufficient interest from industry to warrant establishing licensing agreements. REI holds a license from EPRI that allows REI to utilize RRI technology. Through this license, REI is allowed to enter into sub-license agreements with NOx control equipment implementers that will in-turn market, design and install RRI technology in utility boilers. REI has completed a sublicense agreement with Fuel Tech, Inc. and is negotiating a sub-license with a second implementer. Multiple implementers are desired to ensure utilities can implement RRI on a costcompetitive basis.

For the SCR Catalyst Evaluation task (Task 4) it has been determined that it would be best to perform long-term (six month) tests with the reactor in the field at a utility boiler, rather than using laboratory scale tests. A request for a contract modification to allow this change in the project plan has been submitted to DOE.

\section{Industry Involvement}

On December 14, 2001, project team members from REI met with senior staff members from EPRI at their headquarters in Palo Alto, California. The REI team provided EPRI personnel with an update on project status and latest results. The meeting provided the opportunity to obtain input from EPRI to ensure that our program continues to produce knowledge and technologies relevant to the needs of the US utility industry.

Results from portions of this research program have been reported to industry through technical presentations at two recent conferences.

- A paper entitled "Use of CFD Modeling to Evaluate NOx Reduction Technologies in Utility Boilers" that was presented at the POWER-GEN International Conference held in Las Vegas NV, Dec 11-13, 2001 highlighted the use of CFD modeling to evaluate RRI and other in-furnace NOx control strategies [Adams et al, 2001].

- A paper entitled "On-line Technique for Corrosion Characterization in Utility Boilers" was presented at the United Engineering Foundation Conference on Power Production in the 21 st Century: Impacts of Fuel Quality and Operations, Snowbird, UT, October 2001 in which we described using the corrosion probe to evaluate waterwall wastage in a coal fired utility boiler [Linjewile et al, 2001].

\section{Task 2 - NOx Control - LNFS/SNCR/Reburning}

No substantial technical work was performed on this task during the last performance period. 


\section{Task 3 - Minimization of Impacts}

\section{Task 3.1 Waterwall Wastage}

In this quarter, work on the corrosion probe focused on analysis of data obtained during corrosion measurements at the FirstEnergy Eastlake Power Station, near Cleveland, Ohio. In addition, complimentary laboratory corrosion measurements were conducted at the University of Utah. Much of this work was funded through a grant from the Ohio Coal Development Office. However, technology development that played a critical role in making this field test possible relied heavily upon this DOE supported task and is therefore discussed herein. To help facilitate technology transfer and more rapidly disseminate the knowledge and experience gained from this project, portions of the work described below were presented at a recent Engineering Foundation Conference [Linjewile et al., 2001].

\section{Analysis of Corrosion Measurements At Eastlake Power Station}

Prior to the commencement of this program, the ECN probe had completed over 3000 hours of extensive testing in pilot-scale furnaces. These tests have focused on corrosion mechanisms similar to those encountered in cyclone-fired boilers; where corrosion is limited and likely a result of primarily gas phase mechanisms. At Eastlake, corrosion studies were extended to a fullscale plant to investigate the effects of boiler operating conditions on measured corrosion rate. The effects of boiler load, ash deposition, and excess oxygen concentration were reported in the previous quarter. In this quarter we examined the ffects of boiler load in the light of furnace exit gas temperature (FEGT); and heat flux on corrosion rate. Some previously unresolved issues involving the stability of the measurements are also addressed.

The measurements at Eastlake involved testing at two furnace elevations on the front wall, occasionally referred to as probe locations A and B for the upper and lower furnace elevations, respectively. These were the hottest parts of the boiler where access was possible. The probe sensor elements were maintained at about $450-460{ }^{\circ} \mathrm{C}$. The boiler was operated in a "loadfollowing" mode, as such the load changed according to demand. Therefore testing was conducted at a variety of load and excess $\mathrm{O}_{2}$ levels.

Effect of boiler load and FEGT: Figures 3.1.1 shows a summary of corrosion data gathered in a period of 24 hours, when the probe was installed at the upper furnace elevation. The data shows the measured corrosion rate as a function of boiler load and FEGT. As can be seen in this figure, increasing the boiler load results in an increase in the corrosion rate. It is also apparent that changes in boiler load are closely followed by changes in FEGT. Since the sensor plate temperature is constant, the impact of FEGT on corrosion rate is likely indirect. Past experience suggests that at high load more unreacted fuel and reducing gases reach the wall. 


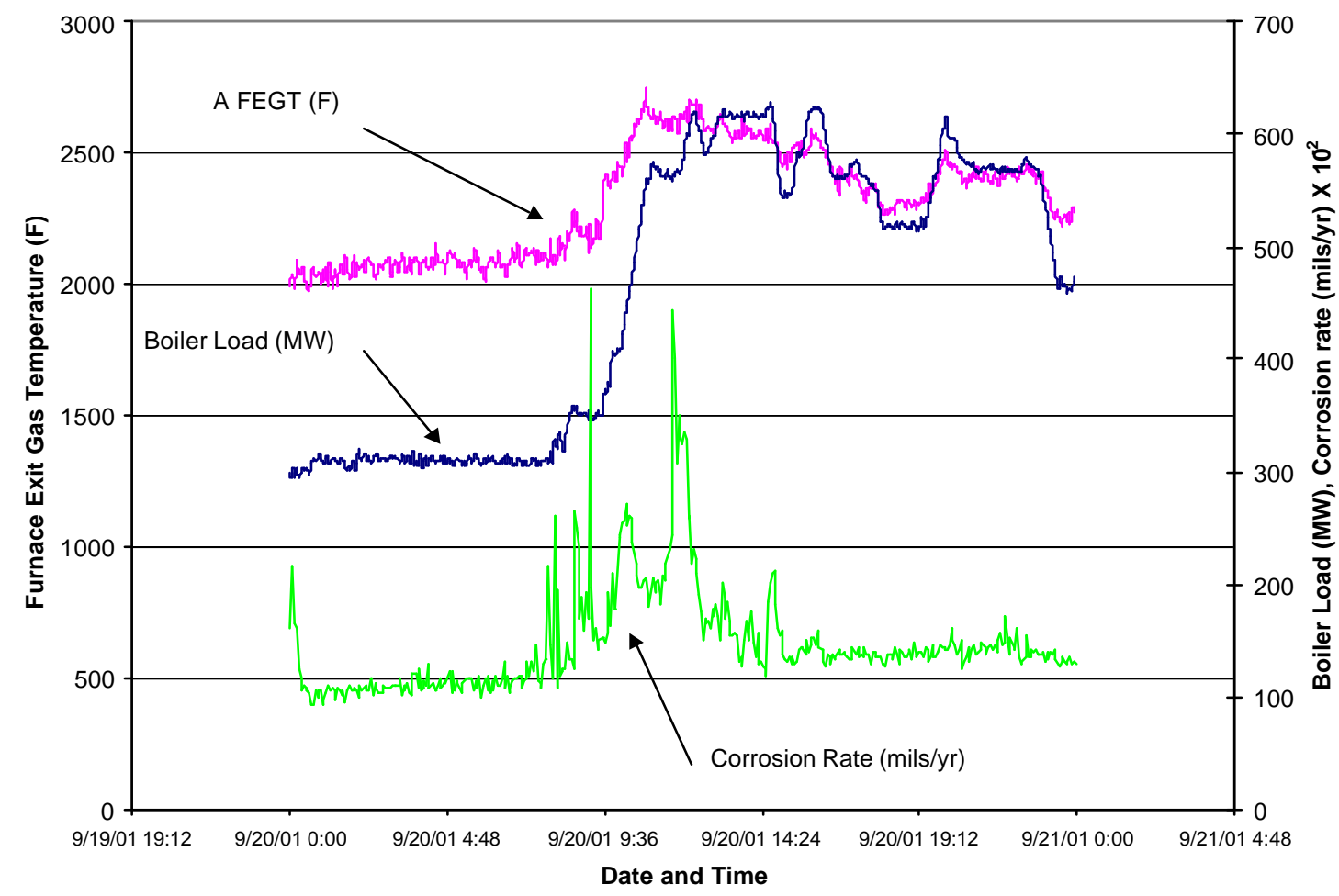

Figure 3.1.1. Corrosion rate and FEGT data during a change in boiler load.

An inspection of the data collected over a period of three weeks showed periods of constant boiler load were at 300, 350, 500 and $600 \mathrm{MW}$. Using these observations it was decided to examine the effects of boiler load and oxygen concentration on corrosion rate. The data were reduced such that average values of corrosion rate and $\mathrm{O}_{2}$ concentration were obtained during the observed periods of constant boiler load. The results of this analysis, presented in Figure 3.1.2, showed that there are definite trends in corrosion rate as a function of boiler load and oxygen concentration. 


\section{6}

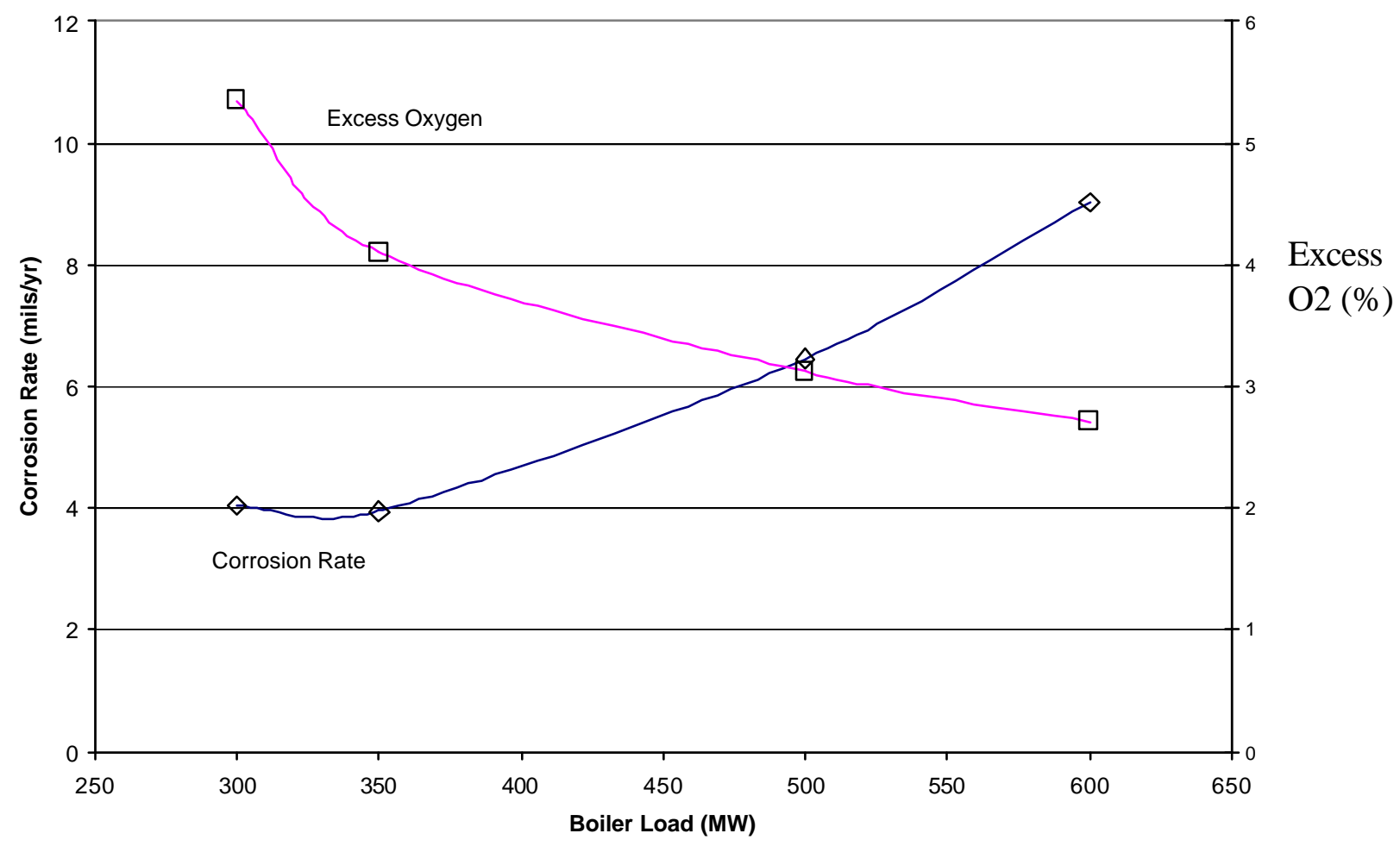

Figure 3.1.2. The effect of steady boiler load and excess oxygen level on corrosion rate.

Effect of Heat Flux: The radiant section of a boiler represents the hottest region of a furnace. Harb and Smith (1990) report that heat fluxes are commonly found in the range $200-500$ $\mathrm{kW} / \mathrm{m}^{2}$. The electrochemical noise probe has never before been tested in this region of a boiler. Previous results (Davis et al., 2000) indicate that high radiant heat fluxes coupled with strong reducing conditions are responsible for enhanced waterwall corrosion for high chlorine coals. It is thought that high heat fluxes on waterwalls can be compounded by flame impingement. Flame impingement may also result in the direct transfer of particulate matter (ash and unburned carbon) to the waterwall tubes. In addition, volatiles may be transferred by this mechanism, leading to existence of reducing conditions.

Stultz and Kitto (1992) present a method for measuring heat fluxes in boiler tubes when the temperatures at two locations in the tube are known. A similar approach was used here to calculate heat flux based on the probe's temperature-sensing element. Figures 3.1.3 shows the summary of local heat fluxes for the lower probe elevation. It appears that the corrosion rate responds to heat flux in the same fashion as boiler load and FEGT. Notice that the regions of high corrosion rate correspond to regions of high heat fluxes. In this installation, soot blowing to remove ash deposits was performed twice in every shift. Soot blowing could result in changes in the heat flux experienced by the tubes and hence influence the corrosion behavior. 


\section{7}

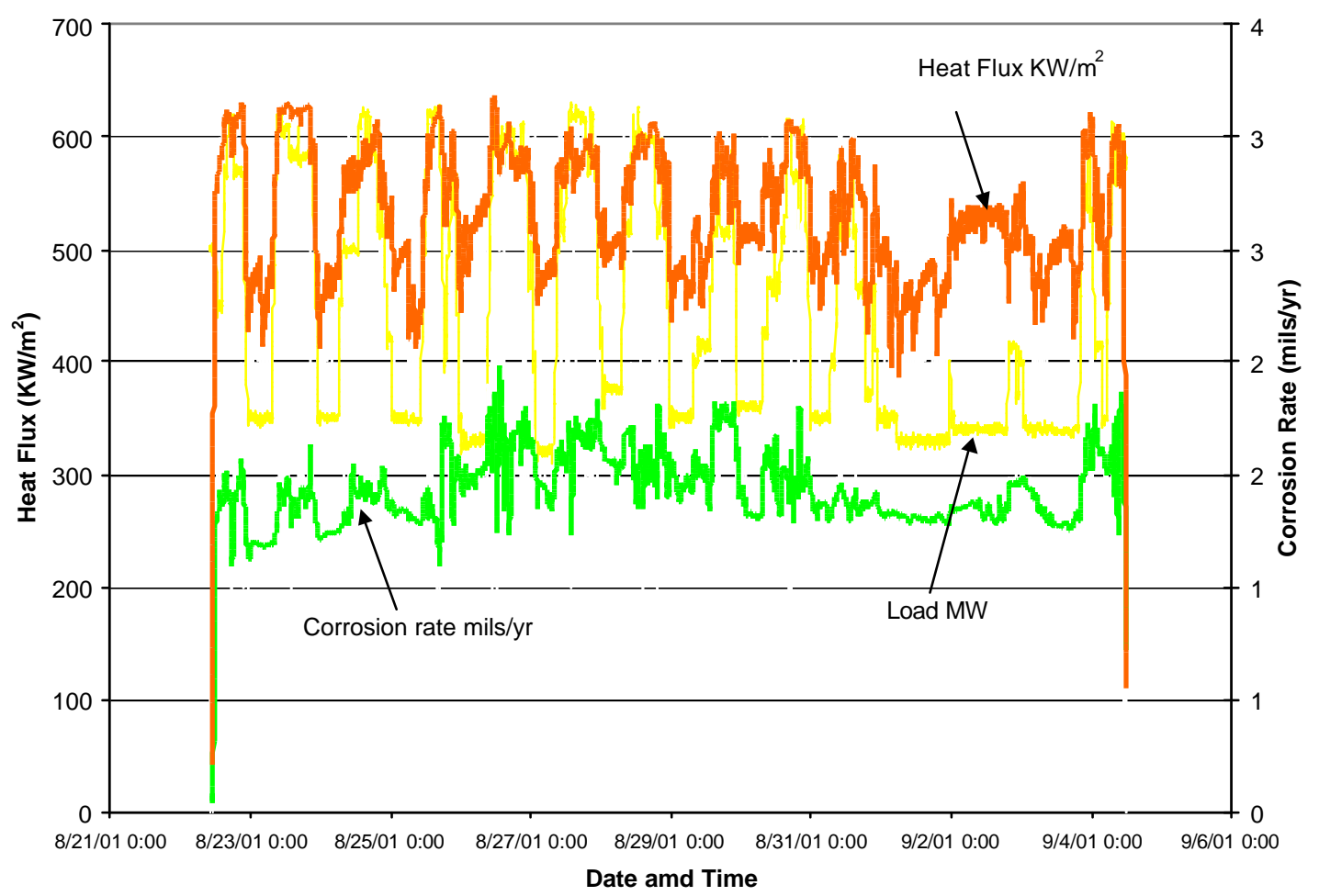

Figure 3.1.3. Effect of heat flux on corrosion rate.

Stability of Measurements: The day-to-day stability of corrosion measurements can be assessed by viewing the daily corrosion rate measurements and how they correlate with the key operating parameter, namely, the boiler load. Figures 3.1.4 and 3.1.5 show two such plots obtained from the lower probe elevation, three days apart. Qualitatively, corrosion activity is less at low boiler loads and the level of fluctuations in measured corrosion rate is more limited. As the load is increased from about $350 \mathrm{MW}$ to $600 \mathrm{MW}$, the corrosion rate also increases with a marked increase in the level of randomness. It is also noted that there was more randomness at the high load on August $26^{\text {th }}$ than on August $23^{\text {rd }}$. In order to improve our understanding of this behavior, we examine the role of FEGT. The variation of boiler load with FEGT for the data of August $23^{\text {rd }}$ and $26^{\text {th }}$ is presented in Figures 3.1.6 and 3.1.7 respectively. An inspection of Figures 3.1.6 and 3.1.7 suggests that the stochastic nature of corrosion reactions observed in Figures 3.1.4 and 3.1.5 somewhat correlates with the fluctuations in FEGT. This observation is more apparent in the data of August $26^{\text {th }}$, where the FEGT appears to be very erratic due to some unidentified operational reasons and the randomness is reflected in the corrosion rate. 
8

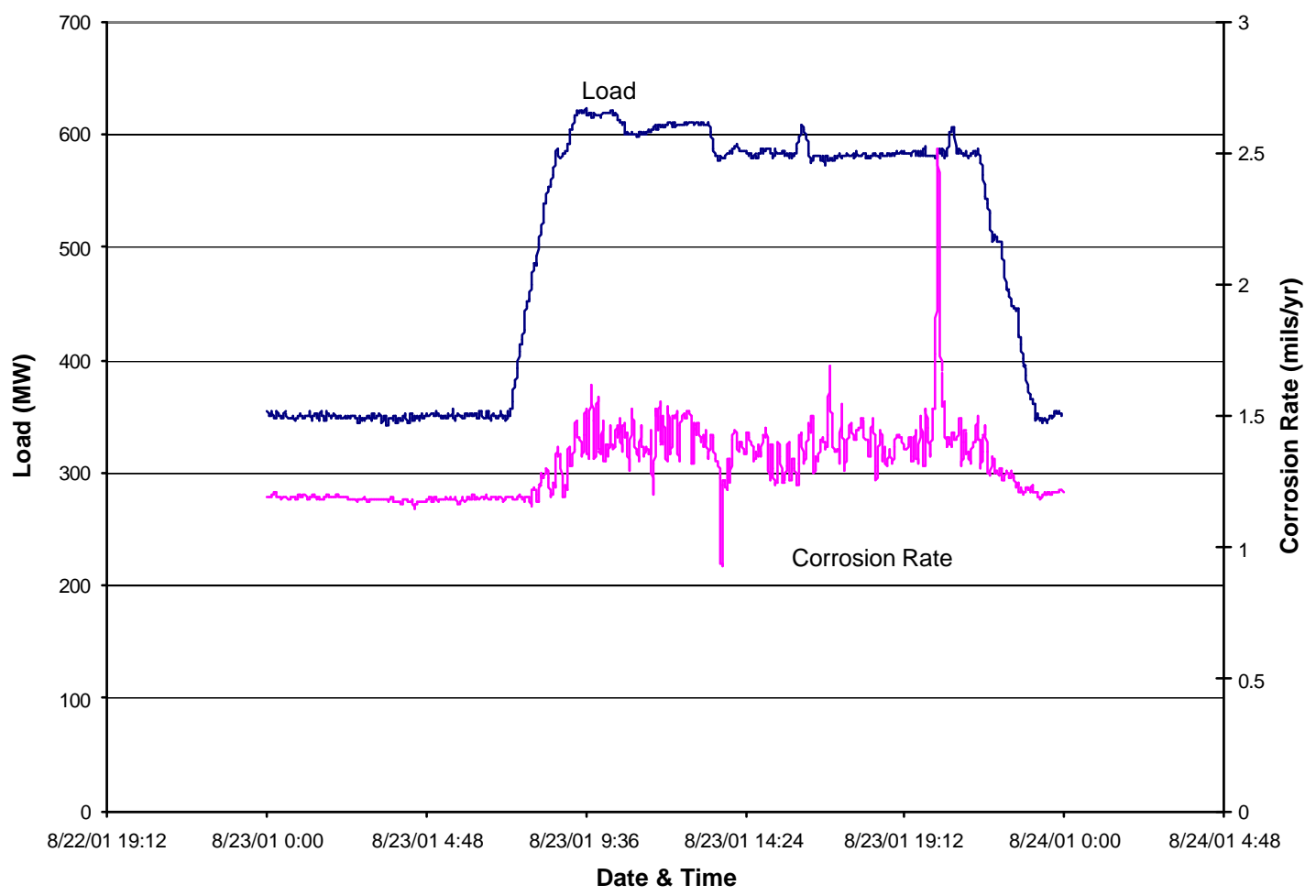

Figure 3.1.4. Corrosion rate and boiler load on August 23, 2001 at the lower probe location. 


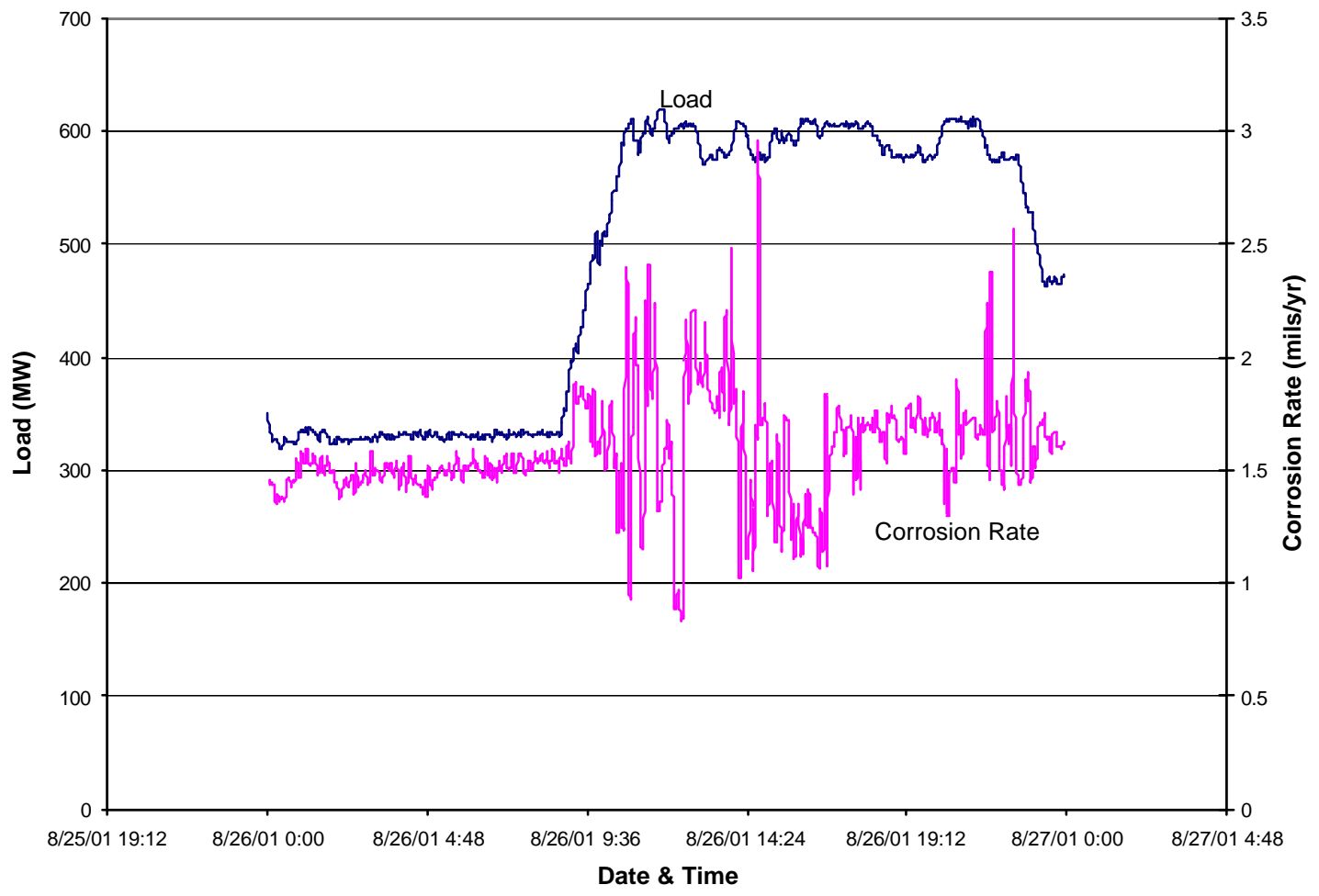

Figure 3.1.5. Corrosion rate and boiler load on August 26, 2001 at the lower probe location. 
10

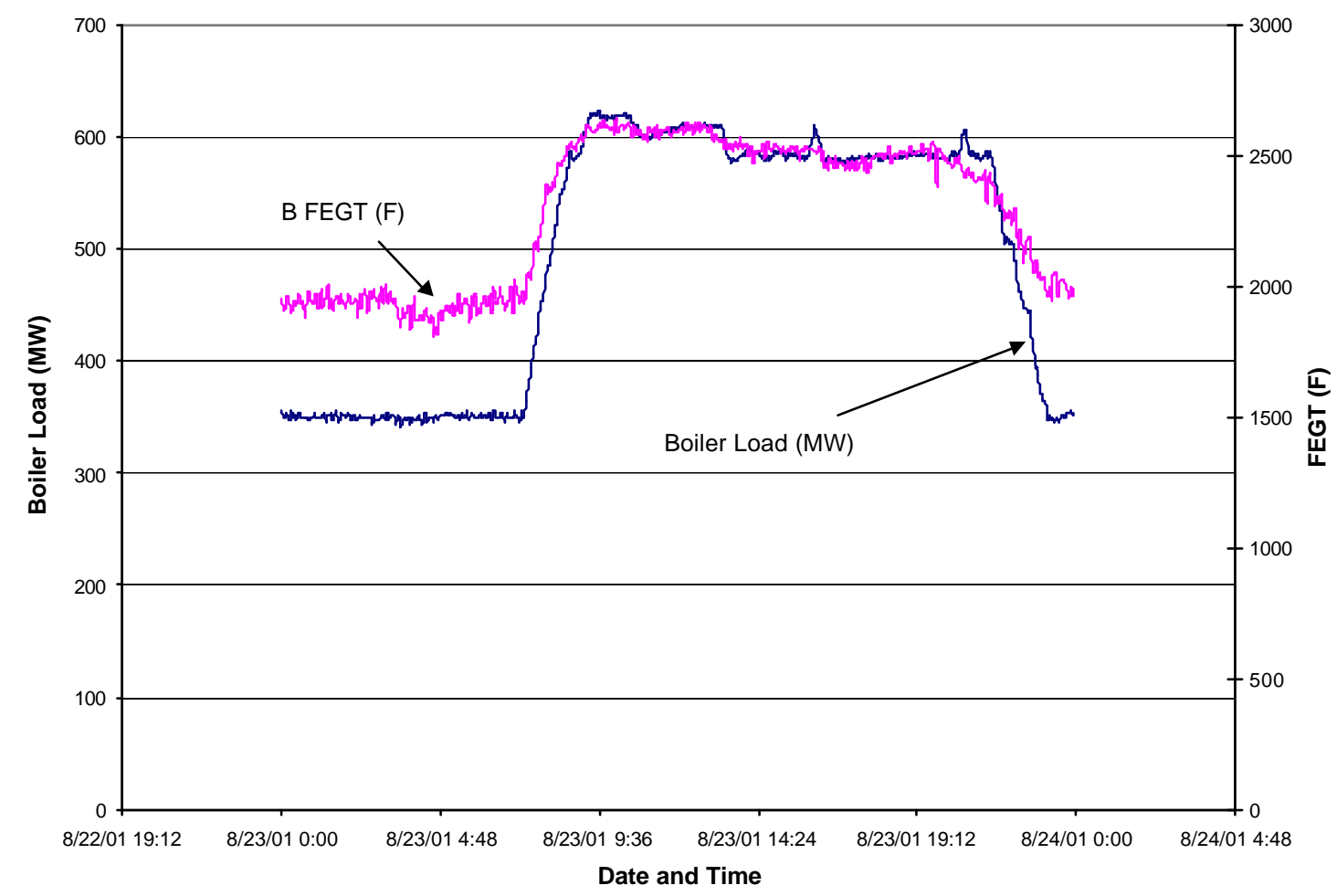

Figure 3.1.6. Variations in boiler load and FEGT on August $23^{\text {rd }}, 2001$ at the lower probe location. 


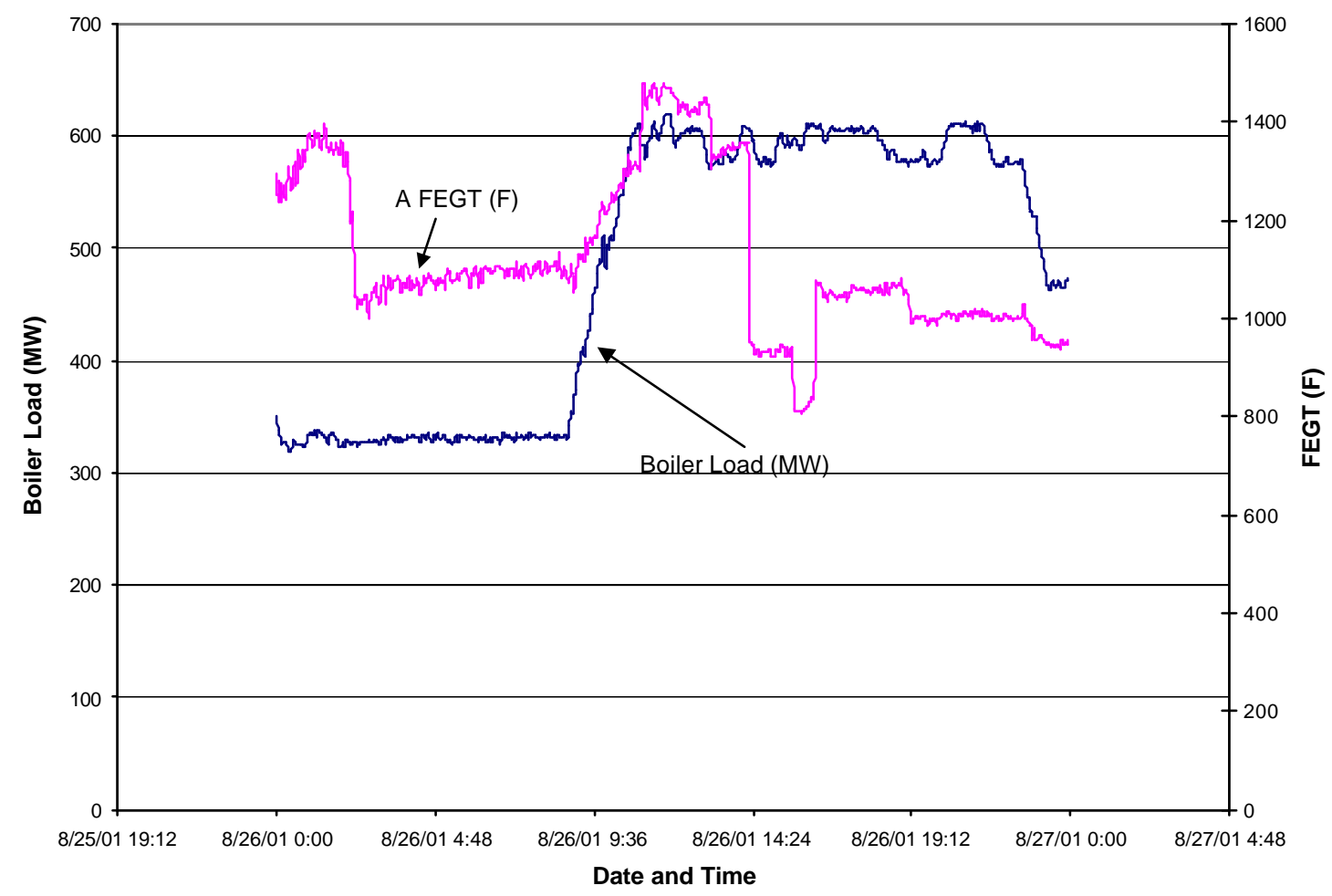

Figure 3.1.7. Variations in boiler load and FEGT on August $26^{\text {th }}, 2001$ at probe location A.

Corrosion Measurement Tests at the University of Utah Combustion Research Laboratory In order to effectively evaluate the behavior of the probe under conditions where stoichiometry and $\mathrm{H}_{2} \mathrm{~S}$ concentration could be independently controlled, the probe was tested in the Ufurnace at the University of Utah as shown in Figure 3.1.8. These tests were used for comparison between electrochemical and profilometric corrosion rates. The six-inch inner diameter Ufurnace is down-fired with a total length of $22 \mathrm{ft}$. The burner is fired in the top of the first section. The coal feed rate is typically eight to ten pounds per hour, and at full load the furnace residence time is $2.5 \mathrm{~s}$. The probe was inserted well downstream of the burner, section 4 of Figure 3.1.8, such that mixing was complete. Staging air was added downstream of the test section. Figure 3.1.9 shows the probe prior to installation into the U-furnace. The gas composition in the testing zone was measured continuously by several analyzers for $\mathrm{CO}, \mathrm{CO}_{2}, \mathrm{O}_{2}$ and $\mathrm{NO}_{\mathrm{X}}$. Hydrogen sulfide composition was measured by an FTIR spectrometer. 


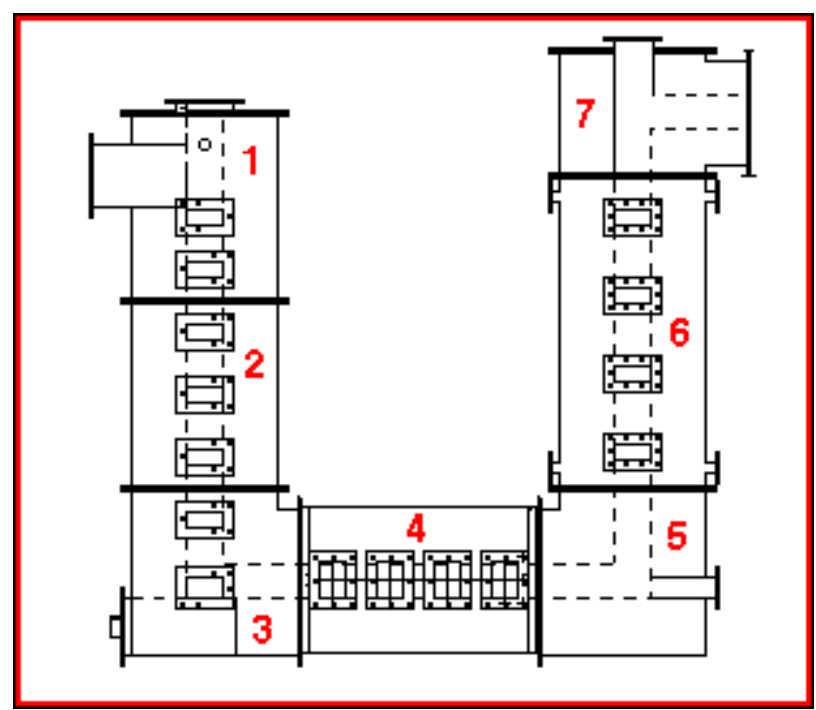

Figure 3.1.8. Schematic of the U-Furnace

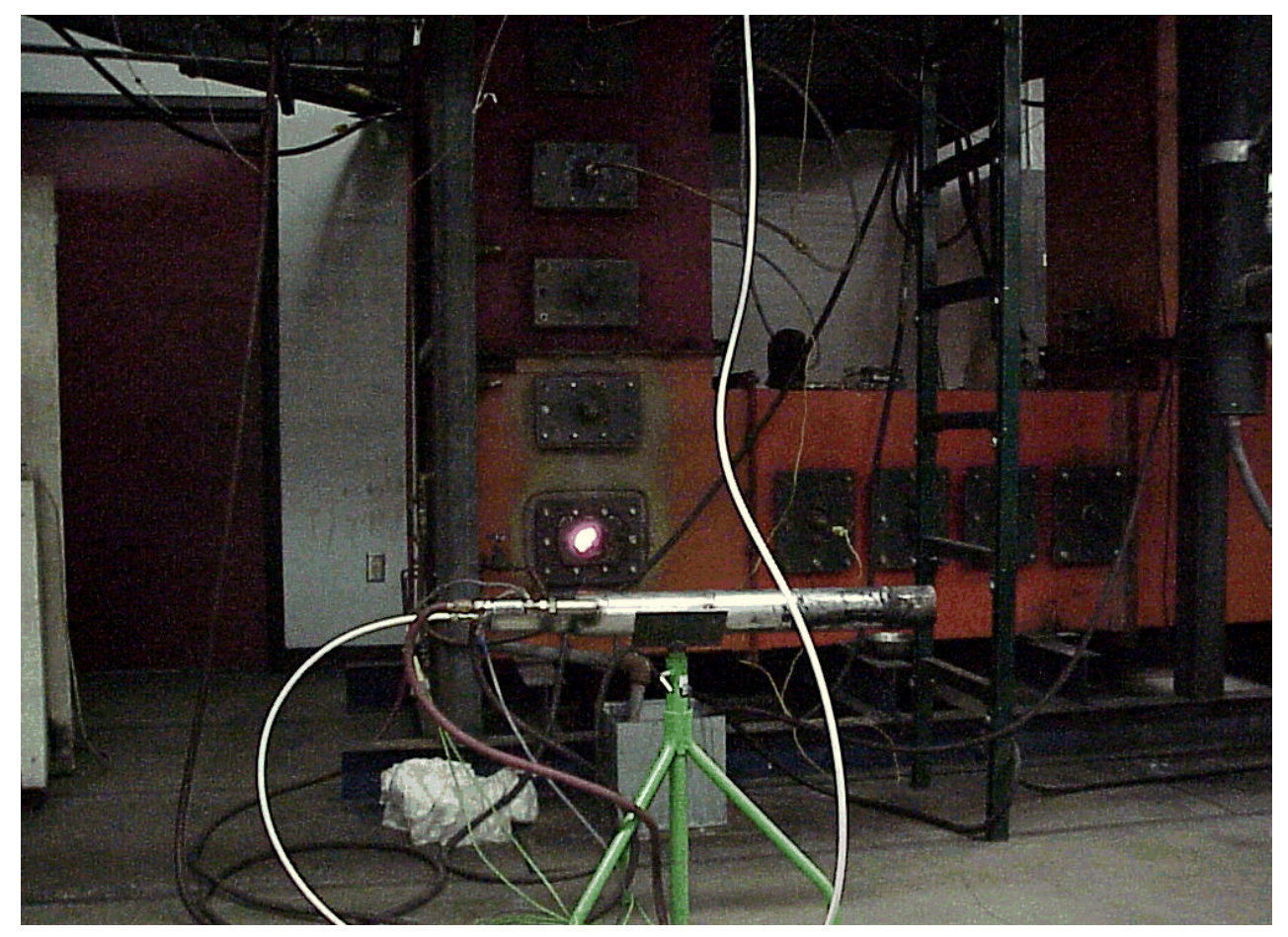

Figure 3.1.9. Corrosion probe prior to exposure in the U-Furnace 
Five tests, shown in Table 3.1.1, were conducted in the U-Furnace at the University of Utah. The stoichiometric ratio for all tests was held constant at 0.85 . The first baseline corrosion test, Run 1a of Table 3.1.1, consisted of exposing the corrosion probe in reducing conditions during combustion of natural gas. This was chosen because of the absence of ash, $\mathrm{H} \mathrm{S}$ and $\mathrm{HCl}$ under such conditions. Figure 3.1.10 shows the observed corrosion rate as a function time for a brief period during the testing. It may be noted that the corrosion rate remained between 0.005 and $0.020 \mathrm{~mm} / \mathrm{yr}$ in the absence of oxygen. The corrosion rate excursions to $0.03 \mathrm{~mm} / \mathrm{yr}$ were observed when the natural gas was burned in oxidizing conditions. Upon switching back to reducing conditions the rate dropped back to the 0.005 to $0.02 \mathrm{~mm} / \mathrm{yr}$ range. It is worth pointing out here that the high temperature corrosion mechanism in this case consists of oxidation/sulfidation reactions. Hence under combustion conditions that exclude $\mathrm{H}_{2} \mathrm{~S}$, the corrosion mechanism is dominated by oxidation of a previously reduced surface.

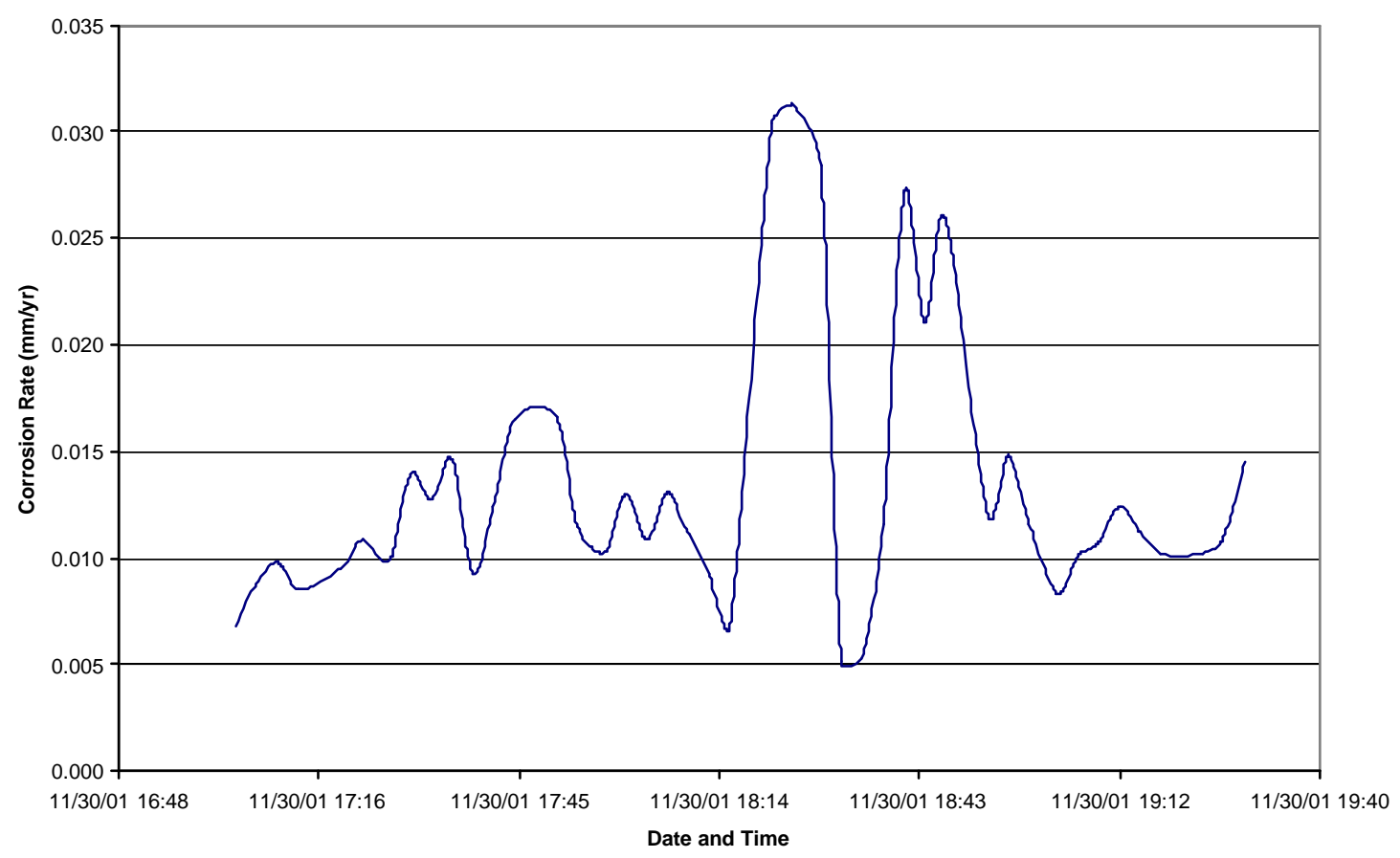

Figure 3.1.10. Baseline corrosion rate in natural gas combustion, Run 1a.

Table 3.1.1. Laboratory test matrix

\begin{tabular}{ccccc}
\hline \hline Run & Description & Fuel & Probe Temperature (C) & Length of Test (days) \\
\hline \hline $1 \mathrm{a}$ & Baseline & Natrl Gas & 450 & 5.1 \\
$1 \mathrm{~b}$ & Baseline & Natrl Gas, Coal & 450 & 0.9 \\
2 & $1000 \mathrm{ppm} \mathrm{H2S}$ & Natrl Gas, Coal & 450 & 4.2 \\
3 & $1000 \mathrm{ppm} \mathrm{H2S}$ & Natrl Gas & 400 & 2.2 \\
4 & $200 \mathrm{ppm} \mathrm{HCl}$ & Natrl Gas & 450 & 1.7 \\
\hline \hline
\end{tabular}


The second baseline test, Run $1 \mathrm{~b}$ of Table 3.1.1, burned coal for the first half and natural gas for the second half of the test in the absence of $\mathrm{H} S \mathrm{~S}$ as shown in Figure 3.1.11. Corrosion was an order of magnitude greater during the combustion of coal than during combustion of natural gas. The inconsistency in the corrosion rate during the firing of coal is due to the sporadic nature of the coal feed system in the U-furnace. The coal feed system produces large periodic upsets in the coal flow rate and thus the oxygen and fuel concentration. During this run, it was observed that changes between reducing and oxidizing conditions occurred every 15 to 30 minutes. Such changes saw carbon monoxide concentrations shoot up well over 3\%. Therefore, it was extremely difficult to maintain a consistent stoichiometry in the furnace for a long period of time. Natural gas was much easier to control due to the nature of the steady feed system.

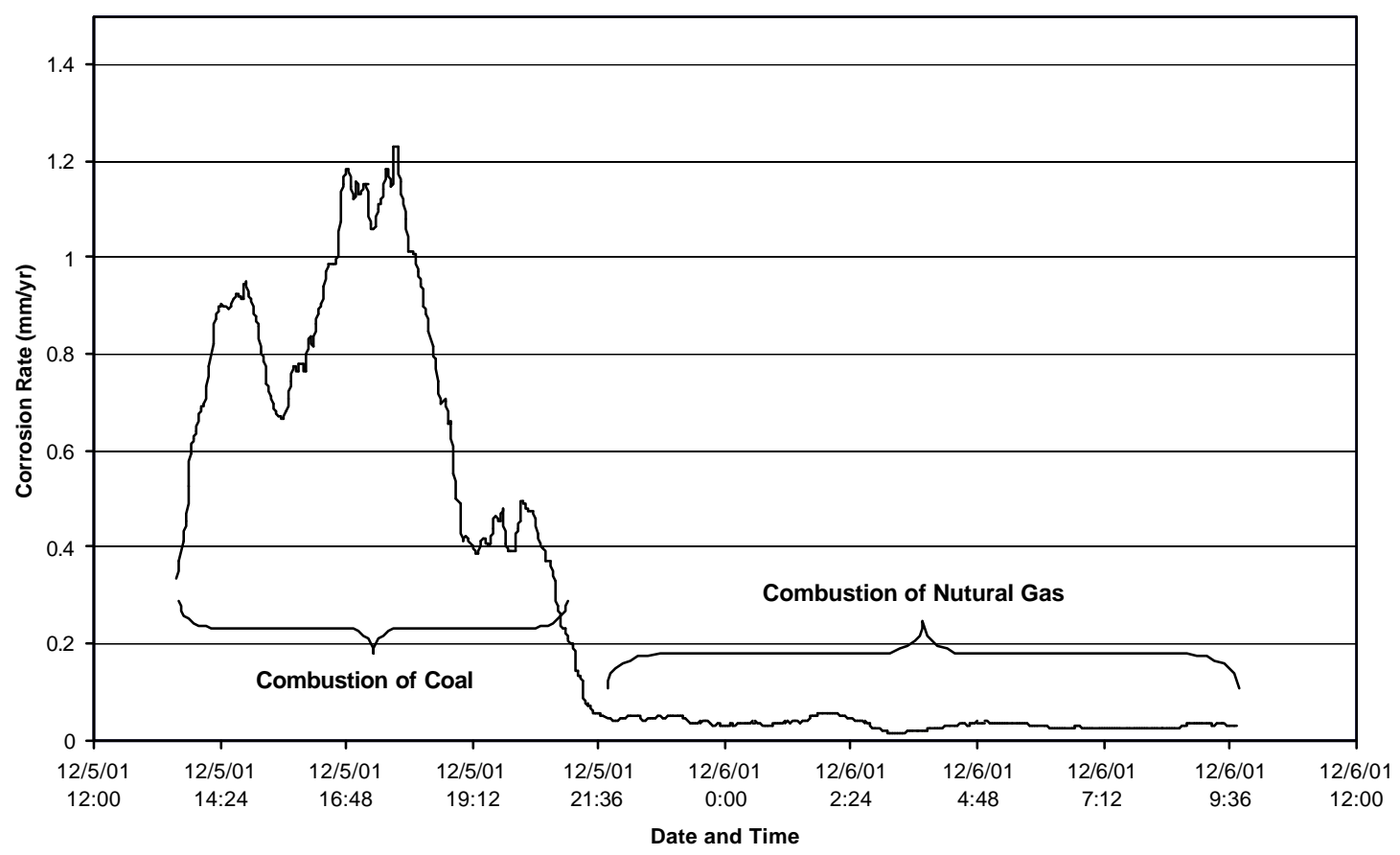

Figure 3.1.11. Baseline Run 1b. Probe response to combustion of coal and natural gas. 
Run 2 of Table 3.1.1 was conducted in the presence of $\mathrm{H}_{2} \mathrm{~S}$ during the combustion of coal and natural gas. Coal was burned during daytime and natural gas was burned at night. $\mathrm{H}_{2} \mathrm{~S}$ was continuously fed to Section 1 in Figure 3.1.8 of the Ufurnace for the duration of the test. The corrosion rate for this test, shown in Figure 3.1.12, is approximately five times that of the baseline tests. One interesting aspect of this test is that the corrosion rate stays relatively constant throughout the test. Only $15 \%$ of the total testing time used coal for fuel, the rest of the test was conducted under natural gas combustion. It should be noted that the largest observed corrosion rate occurred during the baseline Run $1 \mathrm{~b}$. This is possibly due to the massive contribution in corrosion rate during the coal combustion phase. The large corrosion rate was probably a consequence of the alternating reducing and oxidizing conditions discussed previously. The results presented in Figure 3.1.11, Run 1b, suggest that a noticeable difference in corrosion rate should be apparent between the combustion of coal and natural gas; however, this is not the case in Run 2 where coal feeder problems were less severe and hence the dominating factor in corrosion is $\mathrm{H}_{2} \mathrm{~S}$, experienced in both gas and coal combustion.

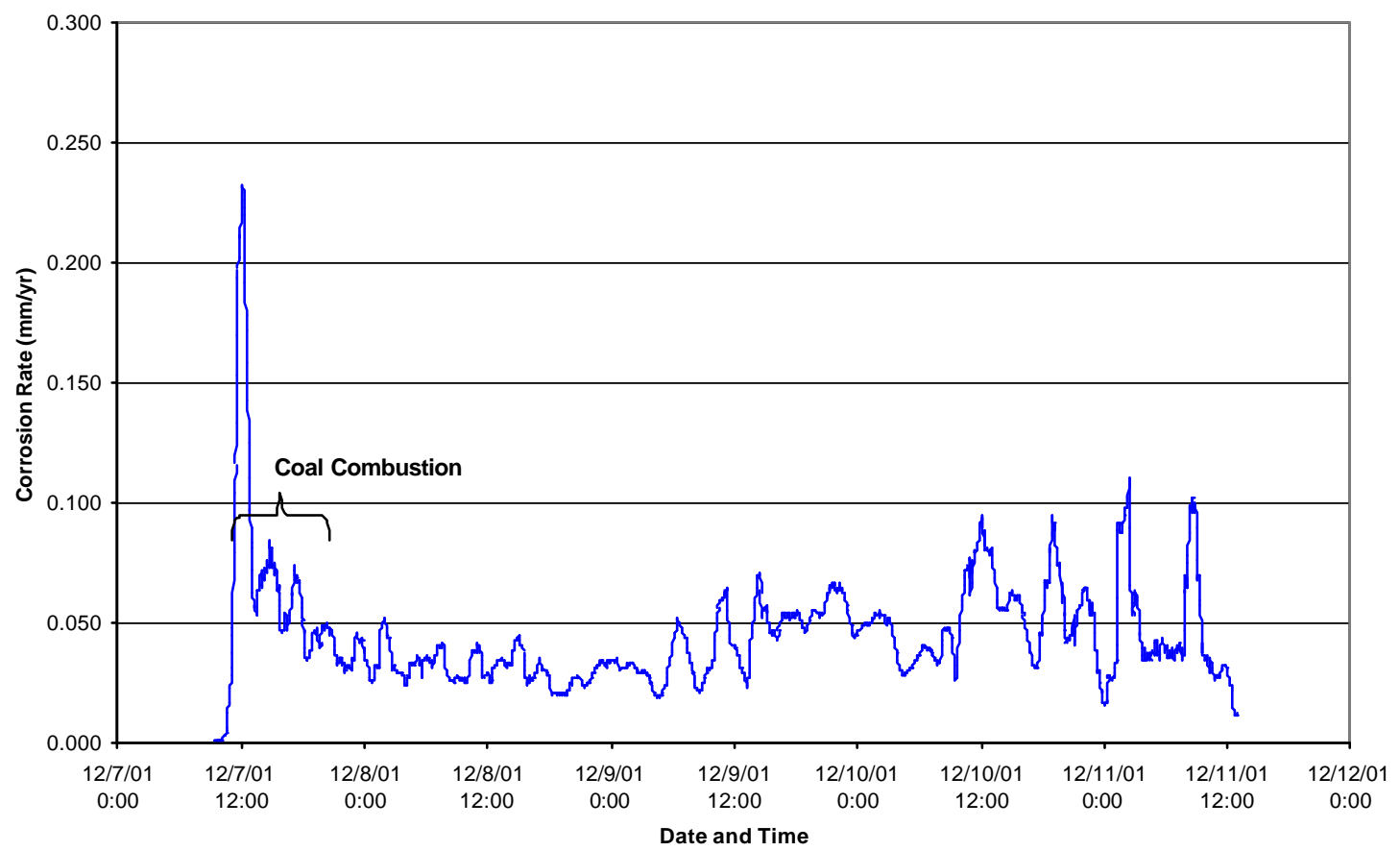

Figure 3.1.12. Run 2. Probe response to $1000 \mathrm{ppm}_{2} \mathrm{~S}$ at $450{ }^{\circ} \mathrm{C}$ in the U-furnace. 
Electrochemical Corrosion Rates and Surface Profilometry: At the end of the testing the representative corrosion rate was determined by integrating the raw electrochemical noise corrosion rate data using the trapezoid rule and dividing the trapezoid sum by the length of the test. The sensor elements were cleaned with Clarke's solution, according to ASTM G1-81 standard practice for cleaning corrosion test specimens. After cleaning, the plates were scanned in a surface profiler for estimation of corrosion depth. A summary of corrosion rates obtained by profilometry and electrochemistry from laboratory tests and fieldwork is presented in Figure 3.1.13.

Probe Calibartion Chart

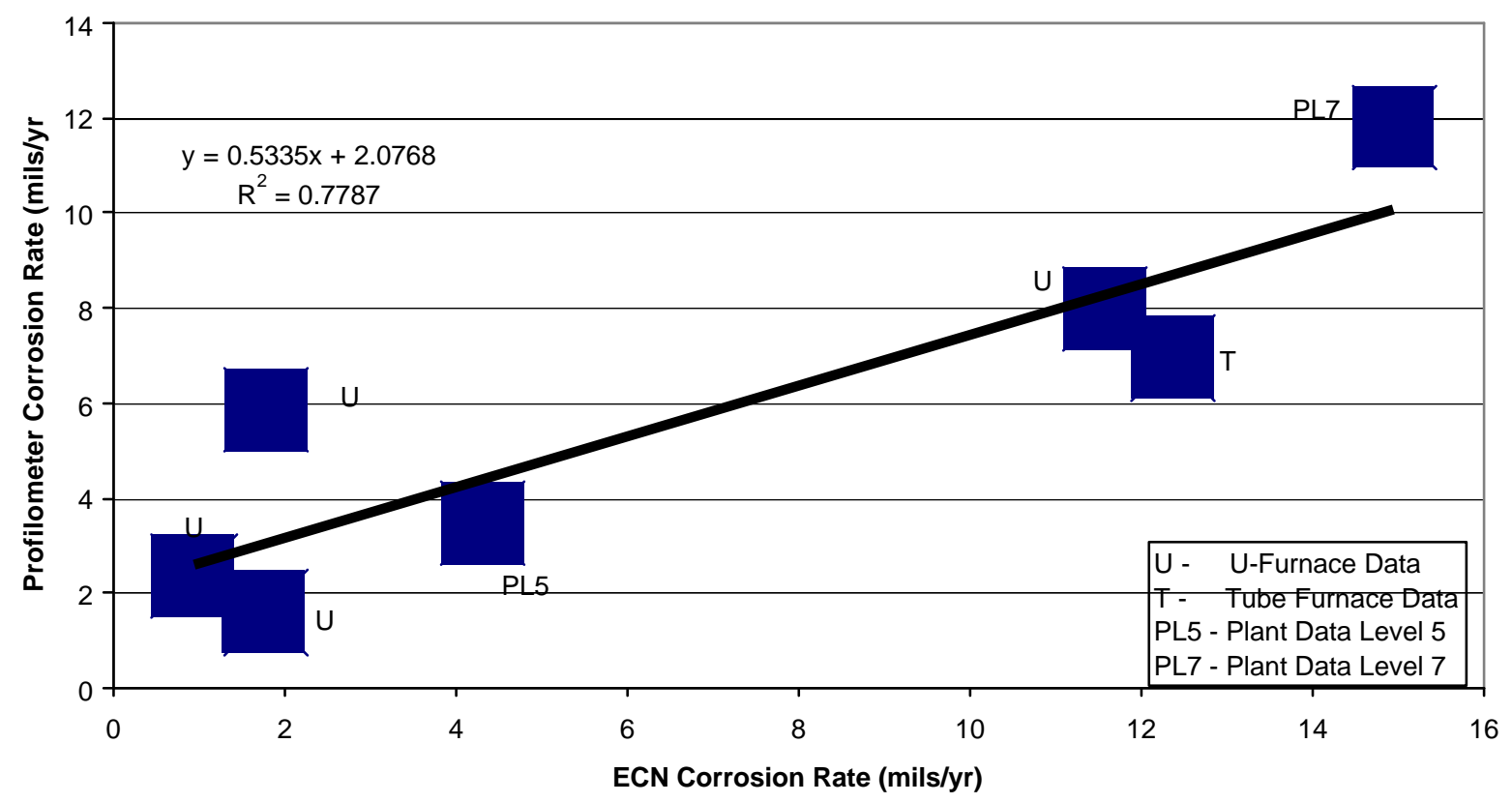

Figure 3.1.13. Calibration of the electrochemical noise probe. 


\section{Task 4 - SCR Catalyst Performance under Biomass Co-Firing}

The purpose of this task is to perform a combination of basic and applied R\&D, with heavy focus on laboratory and field tests, to develop a better understanding of the "real" costs associated with using selective catalytic reduction (SCR) for coal-fired boilers using US coals and a coal/biomass blend. Within this task there are four principal sub-tasks:

Task 4.1: Technology assessment on fundamental analysis of chemical poisoning of SCR catalysts by alkali and alkaline earth materials

Task 4.2: Evaluation of commercial catalysts in a continuous flow system that simulates commercial operation

Task 4.3: Evaluation of the effectiveness of catalyst regeneration

Task 4.4: Develop a model of deactivation of SCR catalysts suitable for use in a CFD code

Sub-tasks 1 and 3 are being principally performed at Brigham Young University under the direction of Professors Larry Baxter and Calvin Bartholomew. The work effort for sub-tasks 2 and 4 is being performed by REI, under the supervision of Dr. Constance Senior, with assistance from the University of Utah (Professor Eric Eddings and Dr. Kevin Whitty) on sub-task 2.

\section{Task 4.1 Technology Assessment}

The objectives of this subtask are (1) to supplement the largely complete SCR-catalystdeactivation literature with results from new laboratory-scale, experimental investigations conducted under well-controlled and commercially relevant conditions, and (2) to provide a laboratory-based catalyst test reactor useful for characterization and analysis of SCR deactivation suitable for samples from commercial facilities, slipstream reactors, and laboratory experiments. Two catalysts flow reactors and several additional characterization systems provide the analytical tools required to achieve these objectives. The flow reactors include the in situ surface spectroscopy reactor (ISSR) and the catalyst characterization system (CCS), both of which are described in more detail below. The ancillary characterization systems include a temperatureprogrammable surface area and pore size distribution analyzer, scanning electron microscopes and microprobes, and catalyst preparation systems.

The sample test matrix includes two classes of catalysts: commercial, vendor-supplied SCR catalysts and BYU-manufactured, research catalysts. The commercial catalysts provide immediate relevance to practical application while the research catalyst provides less fettered ability to publish details of catalyst properties. The five commercial catalysts selected for use come from most commercially significant catalyst manufacturers (Cormetech, Haldor Topsoe, Hitachi, and Siemens) and provide a wide range of catalyst designs and compositions. The inhouse catalyst allows detailed analysis and publication of results that may be more difficult with the commercial systems. This catalyst suite provides a comprehensive test and analysis platform from which to determine rates and mechanisms of catalyst deactivation. The result of this task will be a mathematical model capable of describing rates and mechanisms of deactivation. 
Within the last performance period, design of the reactor systems at BYU was largely completed and installation substantially initiated. Shakedown data from the ISSR were collected and analyzed while construction of the CCS is continuing. The status of major component of the CCS is described first.

\section{ISSR Overview}

The purpose of the ISSR (Figure 4.1.1) is to provide definitive indication of surface-active species through in situ monitoring of infrared spectra from catalytic surfaces exposed $\mathbf{b}$ a variety of laboratory and field conditions. The ISSR provides in situ transmission FTIR spectrometer measurements of $\mathrm{SO}_{2}, \mathrm{NH}_{3}$, and $\mathrm{NO}_{\mathrm{x}}$, among other species. Absorption and desorption behaviors of these and other species are monitored. Quantitative indications of critical parameters, including Brønsted and Lewis acidities on fresh and exposed catalysts will be included. Indications of coadsorption of $\mathrm{NH}_{3}$ and $\mathrm{NO}_{\mathrm{x}}$ will help elucidate mechanisms and rates of both reactions and deactivation.

During this quarter, the ISSR was exercised in shakedown mode and preliminary results were obtained. Several design changes were proposed, mainly dealing with better temperature control of optical components. A detailed report of progress on this reactor will be provided next quarter. The overall flow diagram for the reactor is illustrated in Figure 4.1.1.

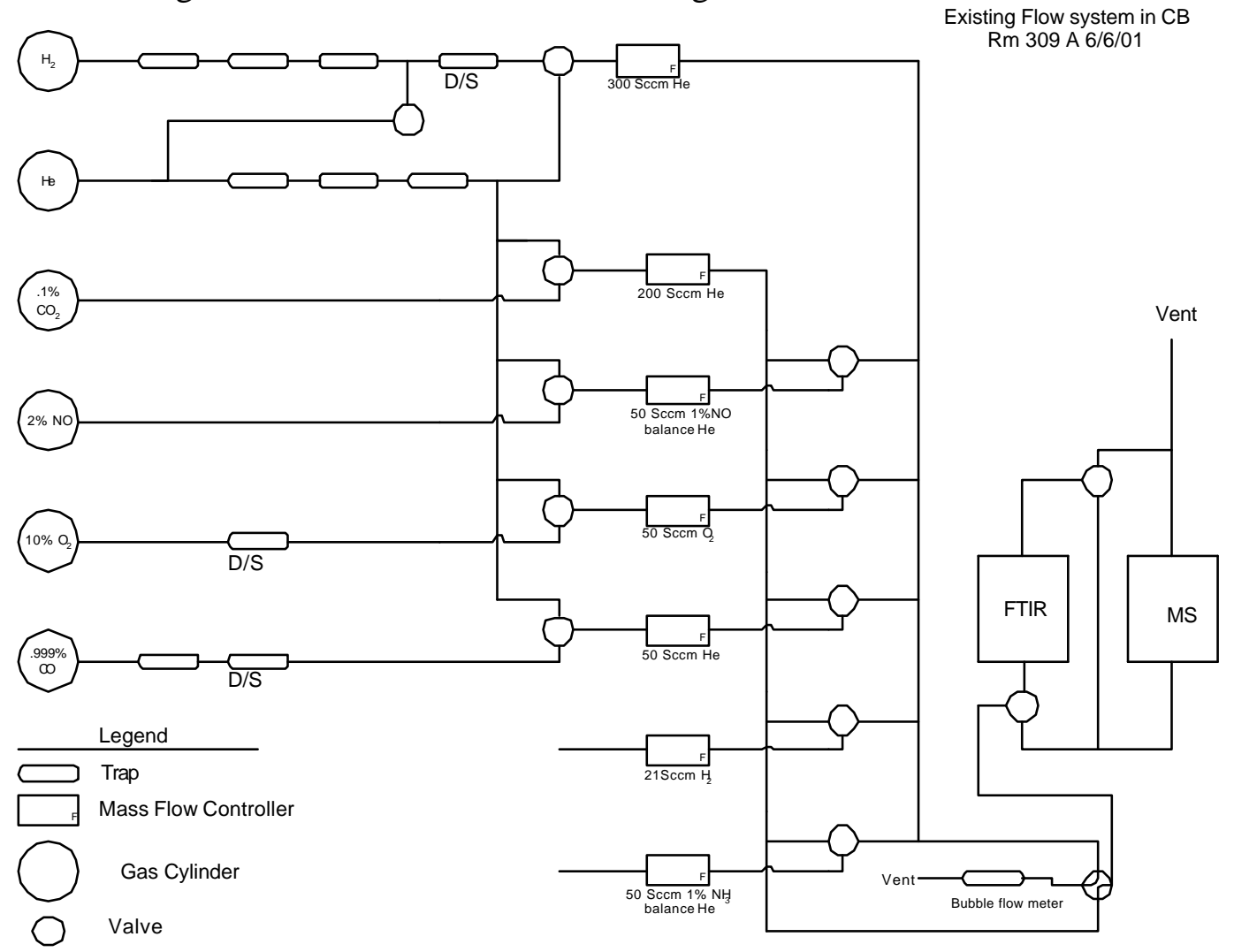

Figure 4.1.1 Overall schematic of the ISSR. 


\section{CCS Overview}

The catalyst characterization system (CCS) provides capabilities for long-term catalyst exposure tests required for ascertaining deactivation rates and mechanisms and a characterization facility for samples from the slipstream reactor to determine changes in reactivity and responses to wellcontrolled environments. Figure 4.1.2 illustrates the essential features of this system up to the analytical train. The analytical train is discussed later. This system simulates industrial flows by providing a test gas with the following compositions: $\mathrm{NO}, 0.10 \% ; \mathrm{NH}_{3}, 0.1 \% ; \mathrm{SO}_{2}, 0.1 \% ; \mathrm{O}_{2}$, $2 \% ; \mathrm{H}_{2} \mathrm{O}, 10 \%$; and $\mathrm{He}, 87.7 \%$.

Flow is generally from left to right in Figure 4.1.1. Gray items represent National-Instruments ${ }^{\mathrm{TM}}$ connected components which is discussed later. Bold lines represent heat-traced flow components, while thin and dotted-thin lines are not heat traced, but are so identified so as to distinguish from the different flow systems.

Both custom and commercial catalysts are tested as fresh samples and after a variety of laboratory and field exposures under both steady and transient conditions

The purpose of the CCS is to quantitatively determine deactivation mechanisms by measuring specific, intrinsic catalyst reactivity of custom (laboratory) and commercial catalysts under a variety of conditions. These catalysts will be impregnated with a variety of contaminants, including $\mathrm{Ca}, \mathrm{Na}$, and $\mathrm{K}$. In addition, the $\mathrm{CCS}$ will characterize samples of catalyst from slipstream field tests to determine similar data and changes in characteristics with exposure. Advanced surface and composition analyses will be used to determine composition, pore size distribution, surface area, and surface properties (acidity, extent of sulfation, etc.).

During this quarter, most of the final designs and specifications were completed and materials were ordered and (mostly) received. Much of the system has been constructed. The various components and their current status are summarized below in the approximate order in which they are encountered by gases flowing through the system.

Helium functions as the carrier gas in this system since molecular nitrogen formed from $\mathrm{NO}_{\mathrm{x}}$ is measured as part of the data analysis. $\mathrm{NO}_{\mathrm{x}}$ derived nitrogen would represent an insignificantly small fraction of total nitrogen if nitrogen where used as a carrier gas. There is no indication in any literature of which we are aware that substitution of helium for nitrogen in any way alters rates or mechanisms of selective catalytic reduction of $\mathrm{NO}_{\mathrm{x}}$ on vanadium-based catalysts.

\section{Gas Cylinders and Manifolds}

Several of the gases used in this experiment are toxic at cylinder concentrations, yet the only feasible storage location of the gases is in the same room as the CCS and, more specifically, the personnel running the CCS. Therefore, standardized gas manifold systems that represent one component for safe handling and use of such gases were developed. Neither BYU nor any of the previous employers of any of the professionals involved in this work publish a standard gas manifold system, so we adapted one used by the PI in similar situations at previous places of employment. The standard system is documented in the Appendix. 
The gas regulator manifold includes pressure relief and shut-off valves that allow the cylinder to be changed with minimal contamination of the system and minimal gas leakage into the room. A vent allows purging of this manifold system and also allows for a release of the gas in case the line over pressurizes.

OSHA-compliant gas cylinder mounting racks and separations are being installed in the laboratory. The College safety department is involved in reviewing all installations and procedures.

Check Valves 1-3 prevent backflow of gases to the cylinders. Two zeolite traps catch hydrocarbon contaminants (if any). These zeolites also trap $\mathrm{SO}_{2}, \mathrm{NH}_{3}$, and $\mathrm{NO}$ are therefore not used on lines designed to contain these gases. Filters 1 and 2 catch zeolite particles that may leave the traps.

\section{Status}

Parts for all manifolds have arrived. Mounting racks and manifolds should be installed early in the next reporting period.

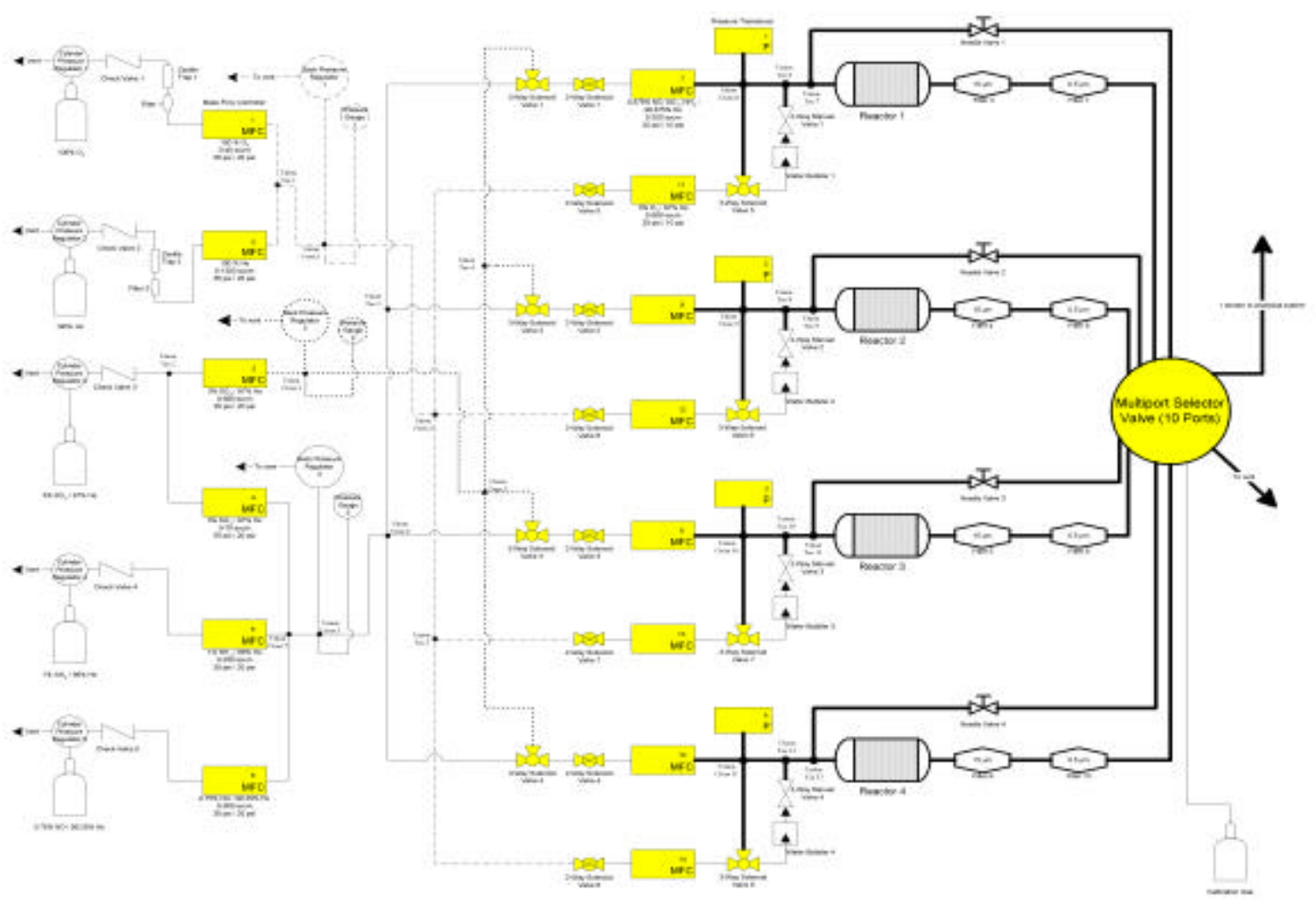

Figure 4.1.2 Summary schematic diagram of the CCS up to (but excluding) the analytical train. 


\section{Mass Flow Controllers and Solenoids}

Mass flow controllers (MFCs) meter a total of five gases, with controllers adapted to specific properties of gases being used where necessary. Solenoids provide automated gas line actuation after the controllers and are part of both the control and the safety system. The controllers allow for both manual and computer interfaces. All require dry gases for accurate control. The MFCs are the first major control component in the flow line. A picture of the current installation is indicated in Figure 4.1.3.

Three basic gas mixture/flow circuits exist. an $\mathrm{O}_{2} / \mathrm{He}$ mixture (Circuit $\mathrm{A}$ ), an $\mathrm{SO}_{2} / \mathrm{He}$ mixture (Circuit B), and an $\mathrm{NO} / \mathrm{SO}_{2} / \mathrm{NH}_{3}$ mixture (Circuit $\mathrm{C}$ ). This design allows for operation of different reactors under different conditions. Table 4.1.1 indicates the flow conditions that correspond with the desired type of operation of each reactor. Each reactor may be operated under such conditions, regardless of what type of flow is fed to any other reactor.

Table 4.1.1 Flow streams used for desired reactor condition.

\begin{tabular}{lc}
\hline $\begin{array}{l}\text { Reactor } \\
\text { Operation }\end{array}$ & Flow Circuits Activated \\
\hline Purge & A only \\
Reaction & A and B \\
Conditioning & C only \\
\hline
\end{tabular}

This design also delays mixing of reactant $\mathrm{O}_{2}$ with $\mathrm{NO}, \mathrm{NH}_{3}$, and $\mathrm{H}_{2} \mathrm{O}$ as long as possible to avoid any premature reactions. Finally, this design avoids dissolution of $\mathrm{NO}, \mathrm{SO}_{2}$, and $\mathrm{NH}_{3}$ in the water bubbler used to humidify the gas fed to the reactors. The $\mathrm{O}_{2}$ and $\mathrm{He}$ in Circuit A carry the water vapor, which mixes with Circuit B just prior to entering the reactor.

Two sets of MFCs, appear in two columns in the drawing. The first set was discussed above. The second set controls flows through Circuits A, B, and/or C so that each reactor receives a constant space velocity. The 2-way Solenoid Valves 1-8 allow each gas stream to be switched on or off, and will fail-to-close so that gas flow can be shut off to each reactor in case of emergency or to change the catalyst. The 3-way Solenoid Valves 1-4 select either Circuit B or C for each reactor as mentioned above. The MFCs are calibrated for the mixture in Circuit $\mathrm{C}$, but also function with mixture in $\mathrm{A}$ and $\mathrm{B}$. It is not crucial that purge and conditioning flow compositions and flow rate be as precisely controlled as the reaction mixture, although simple calibration modifications allow essentially the same precision of control when the system is operated by computer.

Between the sets of MFCs are back-pressure regulators on each of the flow circuits (A, B, and C). These prevent fluctuations in MFC performance that would result from mismatched flow rates between MFCs 1-6 and MFCs 7-14. The pressure gauges next to these regulators indicate pressure fluctuation that affect MFC performance. 


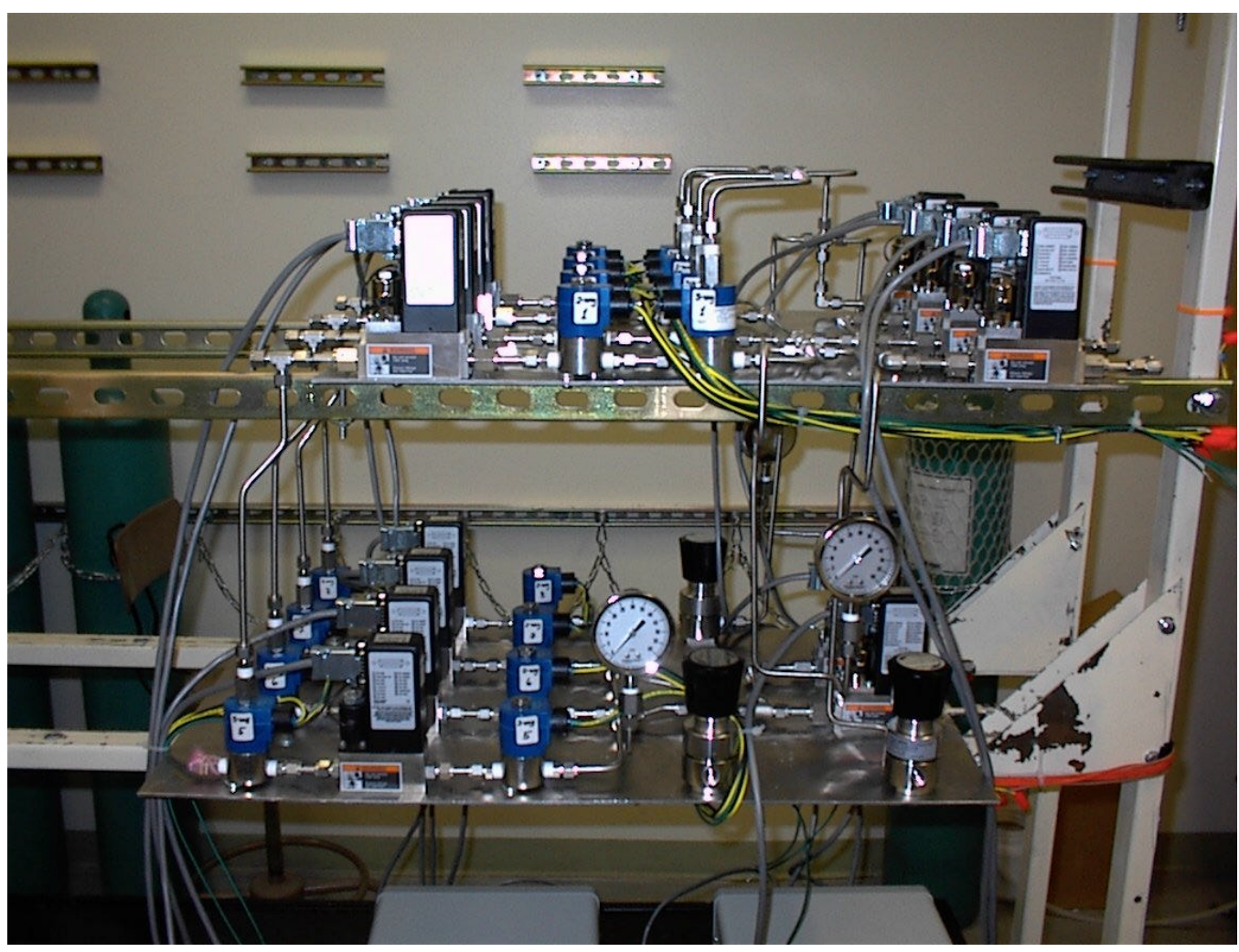

Figure 4.1.3 Mass flow controllers for the CCS.

\section{Status of MFCs}

The MFCs and many of the valves, tubing, and other ancillary components between them and the remaining system are installed. Stainless tubing and Swagelock ${ }^{\mathrm{TM}}$ fittings are used for most flow systems.

\section{Bubblers}

Coal combustion stack gases typically contain about ten percent water vapor. A water bubbler maintains similar water concentrations in the CCS (Figure 4.1.4). The constant-temperature, heated aluminum block of the bubbler determines the water concentration in the exit stream, assuming equilibrium conditions prevail. Each of the four reactor flow lines within the CCS includes an independent bubbler.

$\mathrm{NO}, \mathrm{NH}_{3}$, and $\mathrm{SO}_{2}$ streams bypass the bubbler since water absorbs each of these gases and they are present in small quantities. Furthermore, moisture in gases compromises both the accuracy and the durability of the mass flow controllers, so the bubblers appear downstream of all flow controllers. Helium and oxygen, which comprise the overwhelming fraction of the total gas flow, bubble through the water. The water content of the $\mathrm{He} / \mathrm{O}_{2}$ stream must exceed ten percent for the final concentration to be on target. 
The bubbler design pressure is $34.5 \mathrm{kPa}(5 \mathrm{psig})$ and $70{ }^{\circ} \mathrm{C}$. Each bubbler consumes about $34 \mathrm{ml}$ of water per day. Gravity-driven fill tanks maintain water levels in each bubbler. All tubes downstream of the bubbler are heat traced to prevent water vapor from condensing in the lines.

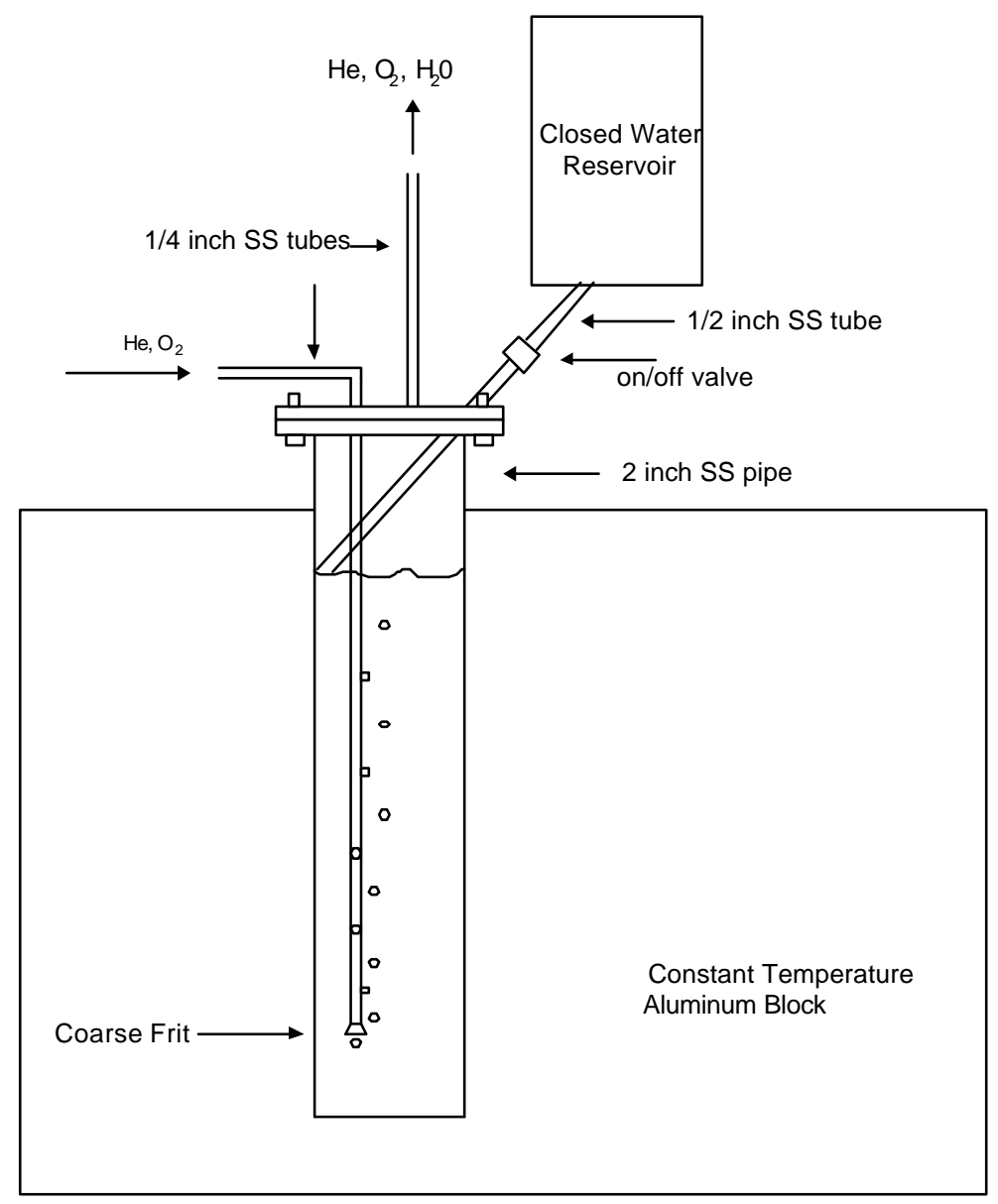

Figure 4.1.4 Schematic diagram of constant-temperature bubblers installed in the CCS.

\section{Status}

The bubbler design and drawing has been completed and submitted to the BYU precision machining lab for construction. The machine shop estimates that the bubbler will be finished by Jan. 20, 2002.

\section{Reaction Chambers}

The four reactor lines in the CCS simultaneously characterize up to four catalysts, one in each of up to four reaction chambers. The CCS includes two types of reaction chambers. The reactor chamber for laboratory samples comprises a $3 / 8$ " tube that houses a powdered catalyst sample. A second reactor chamber provides a site suitable for characterization of the samples from the slipstream field reactor. The second chamber includes a $5.7 \mathrm{~cm}(2.25 \mathrm{in})$ square cross section to match the size of the monolith samples from the slipstream field reactor. The plate-type samples will be cut to fit these dimensions. 


\section{Status}

Two furnaces control the temperatures in two reactors apiece. The furnaces have aluminum inserts that enclose the reactor tubes to facilitate uniform heating. These furnaces have been purchased and installed. They have been mounted vertically, and have digital temperature control.

\section{Filters}

Two sintered metal filters in series follow each reaction chamber. The filters remove particles larger than 15 microns and 5 microns, respectively. The filters protect the downstream analytical equipment. Both catalyst attrition particles and ammonium bisulfate will collect in the filters. Each filter element is replaceable to allow easy maintenance and diagnosis of particulates in the line.

\section{Status}

The filters recently arrived from the manufacturer and are scheduled for installation in early January.

\section{Analyzer Subsystem}

The analyzers at the end of the sample train (Figure 4.1.5) provide quantitative data regarding feed streams and products from the four reaction chambers. The analyzers and ancillary equipment are described in the following section.

\section{Analytical System}

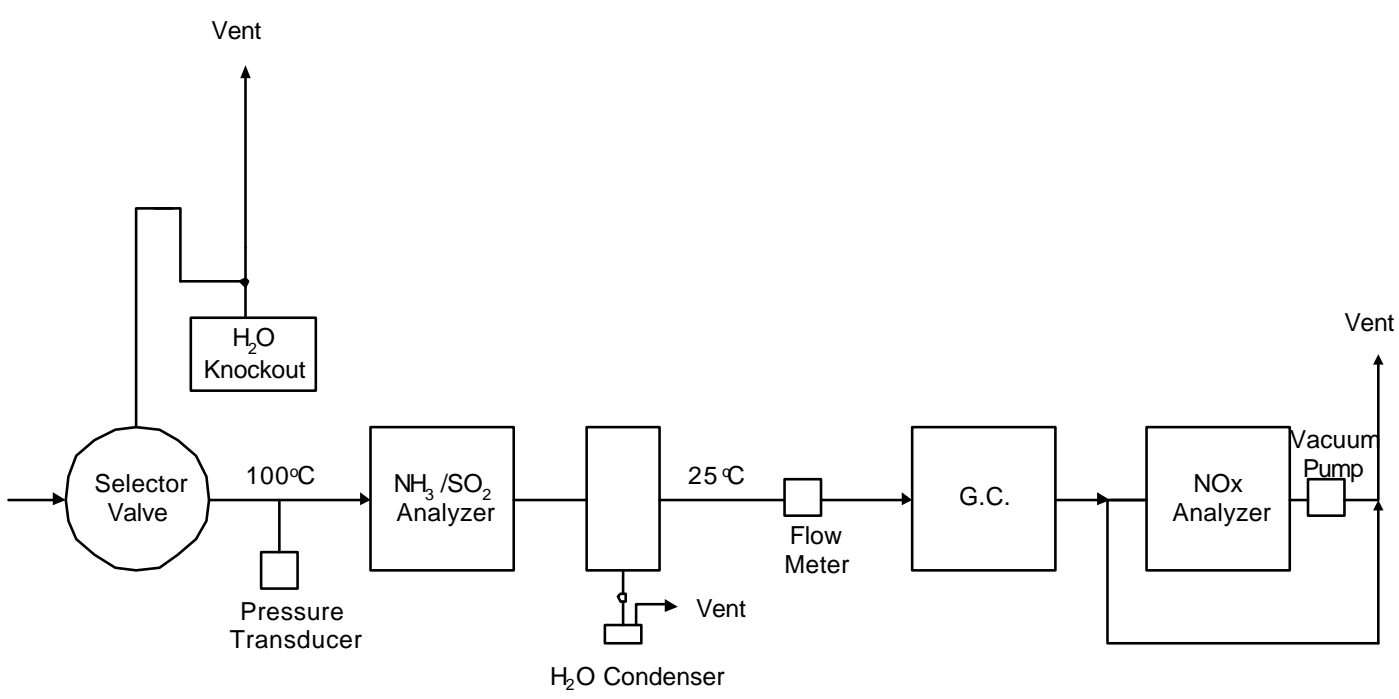

Figure 4.1.5 CCS analyzer subsystem flow diagram. 


\section{Ten-way Selector Valve}

A computer-addressable, ten-way selector valve provides analyzer access to each of the four reaction chamber inlets and each of the four outlets. All streams not directed to the analyzers are combined in a single line that is treated and vented.

\section{Status}

The valve is installed and interfaced with the computer and control system.

\section{$\mathrm{NH}_{3} / \mathrm{SO}_{2}$ Analyzers}

A Rosemount 2000 series ammonia and sulfur dioxide analyzer arrived from the manufacturer this quarter. The analyzer includes heat-traced tubing to prevent condensation.

\section{Status}

The analyzer has been received and is waiting to be installed

\section{Condenser Design}

The condenser dries the sample stream before passing it to the gas chromatograph and $\mathrm{NO}_{\mathrm{x}}$ analyzer. The condenser cools the gas in an ice bath to near $0^{\circ} \mathrm{C}$. The condensate periodically drains through a ball valve.

\section{Status}

The condenser will be installed after the analyzer installation.

\section{Gas Chromatograph System}

The gas chromatograph (GC) works in parallel with the $\mathrm{NO}_{\mathrm{x}}$ analyzer since neither requires high flow rates. The GC quantitatively analyzes for $\mathrm{N}_{2}, \mathrm{O}_{2}$, and $\mathrm{N}_{2} \mathrm{O}$ using helium as a carrier gas.

\section{GC Status}

The GC scheduled for installation in this system comes from previous systems in the lab where it has an established record for reliable and accurate results. Installation will follow that of the condenser.

\section{$\mathrm{NO}_{\mathrm{x}}$ Analyzer}

The Thermo Environmental Instruments Model $42 \mathrm{H}$ chemiluminescence $\mathrm{NO}_{\mathrm{x}}$ analyzer quantifies the $\mathrm{NO}$ and $\mathrm{NO}_{2}$ concentrations in a sample stream. Installation of this analyzer will follow that of the upstream systems.

\section{Data Acquisition and Control Systems}

The CCS is designed to allow manual control of all components. However, computer-based data acquisition and control provide more convenient and possibly more reliable means of collecting data during the long-terms tests for which the CCS is designed. National Instruments ${ }^{\mathrm{TM}}$ LabVIEW $^{\mathrm{TM}}$ software provides the data acquisition and control platform for the CCS. The relatively recent FieldPoint ${ }^{\mathrm{TM}}$ technology is used to manage the acquisition and control signals, providing several operational and reliability advantages. 
Fourteen FieldPoint ${ }^{\mathrm{TM}}$ modules acquire the data on our system. The modules are networked according to the following figure.

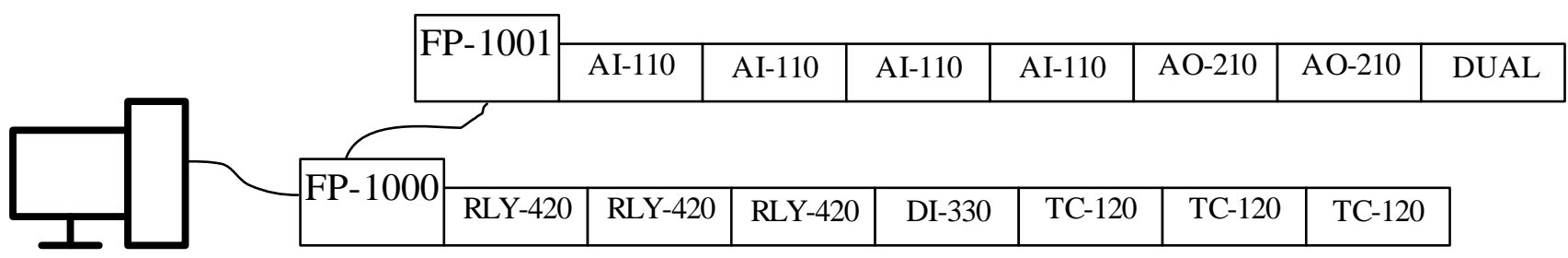

Figure 4.1.6 FeildPoint ${ }^{\mathrm{TM}}$ module network scheme (cross reference with Appendix).

FP-1000 represents the base FieldPoint ${ }^{\mathrm{TM}}$ module. It connects to the computer through a serial cable. The speed of the protocol through the serial cable is sufficient for the needs of this experiment. The FP-1000 uses an Optimux protocol to communicate with the other modules on the network. The relays (RLY-420), digital input (DI-330), and thermocouple modules attach to the main terminal. This allows optimal placement for the RLY and DI to control the multiposition valve actuator after the reactors and gather data from the thermocouples, but will require the extended wiring of the RLYs to the solenoid valves. The networked FP-1001 controls the mass flow controllers (MFCs) and resides close to the MFCs. However, since the analytical system requires wiring to the $\mathrm{AI}$, the dual control module (which allows control of the analytical devices) is placed on this module sequence as well. All of the channels on all modules are summarize in Appendix 1.

Wiring is considered second in priority to instrumentation placement. Lengths of wires that carry analog signals are minimized while those that carry digital signals or only voltage don't matter. For this reason, solenoid valves were wired across the system to a power supply placed out of the way on a shelf high above the insulated furnaces. The solenoid valves are wired especially to allow either manual control or computer control. To avoid confusion they are first wired to a master toggle switch that controls whether manual or FieldPoint ${ }^{\mathrm{TM}}$ will actuate the solenoid valves.

The solenoid wiring and control scheme (Figure 4.1.7) provides safety and operational control for the gases used in the CCS, several of which are toxic at gas cylinder concentrations. A representative wiring diagram for this system is summarized in Figure 4.1.7. Both manual and automated switching of individual solenoids is provided with manual switching overriding the automated system. A master manual switch is provided primarily for safety (emergency shutdown) reasons. To avoid clutter, only three of sixteen wiring and control loops are illustrated. 


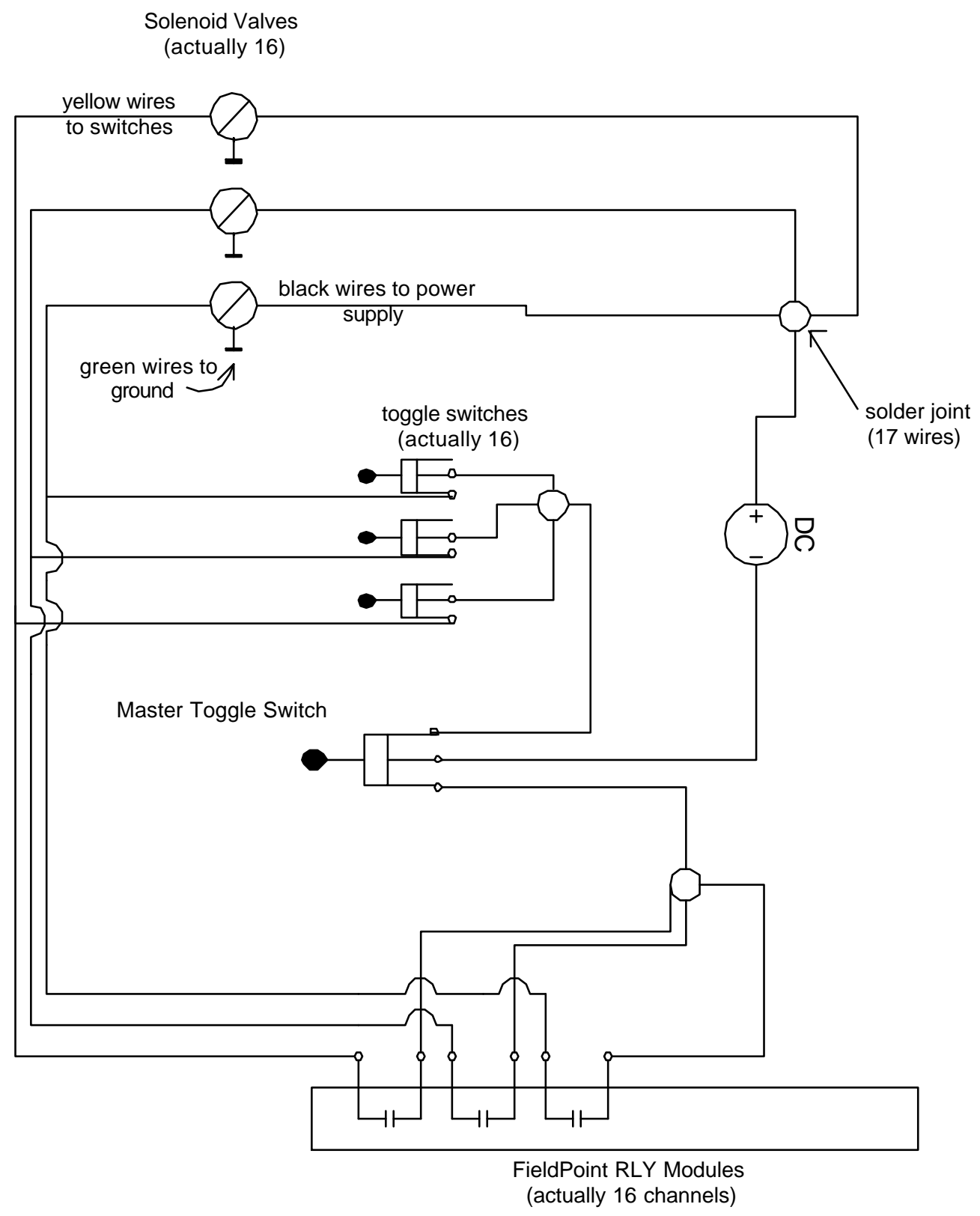

Figure 4.1.7 Schematic wiring and control diagram for solenoid operation in the CCS.

Gases pass through the solenoids and mass flow controllers into bubblers ( $\mathrm{He}$ and $\mathrm{O}_{2}$ only) and mixing plenums, eventually arriving at the reaction chambers. The reaction chamber control system (Figure 4.1.8) provides, as currently configured, three types of actions. The logic diagram for these actions indicates automated control sequences for purging, conditioning, and running each reaction chamber. These conditions combine with conditions with the reactor off and the furnace door open to define the five current computer-controlled operating conditions of the system. Specifically, these conditions are as follows: 
1. Reactor Purge This function serves the purpose of not only clearing the lines to the reactor, but also clearing the gas in the catalyst. The following logical steps are required to purge the reactor:

a. Communicate to the multi-position valve actuator to skip over both the feed and the reactor exhaust because it does not need to be analyzed. This will increase the amount of analysis on the other reactor during this time.

b. Switch the 3-way solenoid valve 5, 6, 7, or 8 away from water bubbler. (Which solenoid switched depends, of course, on which reactor has been selected to purge. Reactor 1 purge will require 3way solenoid 5 to be switched etc.)

c. Set MFC 7, 8, 9, or 10 to zero. The purge gas will be a $\mathrm{He} / \mathrm{O}_{2}-$ only mixture. (Again, set the MFC that corresponds with the appropriate reactor. Reactor 1 purge will require MFC 7 to be set to zero.)

d. Switch 2-way solenoid valve 1, 2, 3, or 4 closed. This will be closed to prevent back flow and increase safety while this line is not in use.

e. Recalculate MFC 3, 4, 5, \& 6 . The flow rate needed from these will decrease because this gas mixture is no longer needed through the reactor.

f. Recalculate MFC $1 \& 2$. These values will probably not change, but it is good practice to recalculate all initial MFC set points for any experimental changes.

2. Reactor This function serves the purpose of possible studying catalyst Conditioning activation. (As seen, for example, in Dynamic Investigation of the Role of Surface Sulfates in $\mathrm{NO}_{x}$ Reduction by Orsenigo etal) Also, to obtain optimal results we will want to condition the catalyst before every run. The following steps are required to condition the reactor:

a. Check multi-position-valve to vent? (It is to take data points to analyze the changes in concentration during a conditioning run. If so, the feed and reactor exhaust are directed to the analyzers rather than vented.)

b. Switch 3-way solenoid valve 1, 2, 3, or 4 from $\mathrm{SO}_{2}$.

c. Open 2-way solenoid valves $1 \& 5,2 \& 6,3 \& 7$, or $4 \& 9$.

d. Switch 3-way solenoid valve 5, 6, 7, o r 8 to bubbler??? (It is unclear that this point if water is desired during condition of catalyst.)

e. Calculate MFC $7 \& 11,8 \& 12,9 \& 13$, or $10 \& 14$.

f. Recalculate MFC 1 through 6.

3. Run Catalyst This is the central function of the reactor and main purpose for Test building this reactor system. It will involve the full capacity of the analytical system and will, of course, require the most precise programming. The following basic steps will be required. 
a. Confirm that Purge and Conditioning has been performed.

b. Open 2-way solenoid valves $1 \& 5,2 \& 6,3 \& 7$, or $4 \& 9$.

c. Switch 3-way solenoid valve 5, 6, 7, o r 8 to bubbler.

d. Switch 3-way solenoid valve 1, 2, 3, or 4 from $\mathrm{NO}_{\mathrm{x}}$.

e. Calculate MFC $7 \& 11,8 \& 12,9 \& 13$, or $10 \& 14$.

f. Recalculate MFC 1 through 6.

g. Allow multi-position valve to choose for analysis.

h. Set $\mathrm{NH}_{3} / \mathrm{SO}_{2}$ Analyzer controls and acquire data.

i. Set G.C. Analyzer controls and acquire data.

j. Set $\mathrm{NO}_{\mathrm{x}}$ Analyzer controls and acquire data.

4. Reactor Off Currently, there are two reactor in one furnace. The procedure if this option is selected will be to:

a. Purge the reactor for a specific amount of time.

b. Switch 2-way solenoid valves $1 \& 5,2 \& 6,3 \& 7$, or $4 \& 8$ closed.

c. Set MFC $7 \& 11,8 \& 12,9 \& 13$, or $10 \& 14$ to zero.

d. Recalculate MFC 1 through 6.

5. Open Furnace This is a function separate from the turning the reactor off, because of Door the fact that each reactor shares the furnace with another reactor. If the door were to be opened prematurely noxious and hot has would be released into he room. This function ensures that the furnace door is safe to open. It only requires to time consuming steps:

a. Run reactor off function for reactor selected.

b. Check and make sure companion reactor is off. 


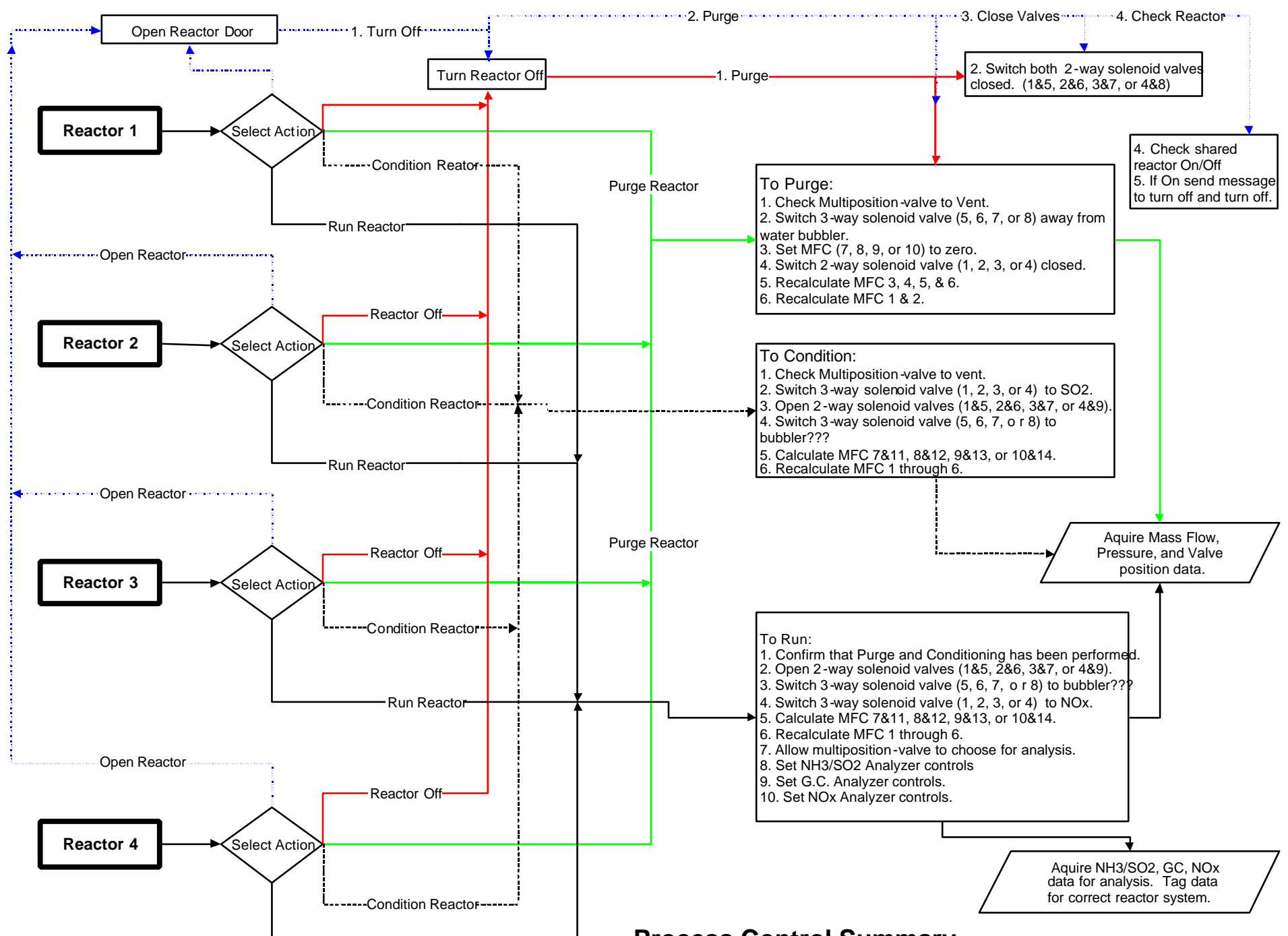

Run Reactor

Process Control Summary

start with reactors

Figure 4.1.8. Reaction chamber process control summary.

\section{Catalyst Preparation}

Commercial and laboratory catalysts provide the basis for data analysis in these systems. The primary purpose for including a laboratory catalyst revolves around unrestricted publication of all properties and property changes it exhibits during testing. The BYU SCR group is therefore preparing this catalyst for both characterization in our laboratory reactors and installation in the field reactor. 
The Ti-W-V laboratory catalyst simulates many aspects of a typical industrial catalyst. Atomic ratios of $90 \% \mathrm{Ti}: 8 \% \mathrm{~W}: 2 \% \mathrm{~V}$ typify commercial catalysts. The species present in the final (preconditioned) catalyst include $\mathrm{TiO}_{2}, \mathrm{WO}_{3}$, and $\mathrm{V}_{2} \mathrm{O}_{5}$. The raw materials used to produce these species include anatase $\mathrm{TiO}_{2}$ powder, ammonium metatungstate, and ammonium metavanadate.

Two types of catalyst will be prepared - a catalyst powder and a catalyst coated monolith. The powder catalyst includes the anatase form $\mathrm{TiO}_{2}$ impregnated with the vanadium and tungsten in a solution followed by drying and calcining in air. This results in a metal oxide catalyst. Dow Corning provided ceramic monoliths that will be used to prepare the wash-coated catalyst. These coated monoliths will be installed in the SCR field reactor. The basic procedure to prepare the coated monolith is:

1. Cut the monolith into pieces suitable to fit into the field reactor (approx 2.25" squares).

2. Immerse the monolith pieces into an acid bath to roughen the surface.

3. Grind some of the $\mathrm{TiO}_{2}$ to a particle size suitable to form a composite.

4. Prepare a slurry of the $\mathrm{TiO}_{2}$ to incipient wetness.

5. Dip and dry the monolith repeatedly to the desired weight percent of $\mathrm{TiO}_{2}$.

6. Prepare a solution of the tungsten and vanadium.

7. Dip \& dry the monolith repeatedly to the desired weight percent of tungsten and vanadium.

8. Calcine the monolith in air to leave only the desired metal oxides in the wash coat.

\section{Status}

The catalyst preparation is underway. All necessary reagents and equipment are ready and monoliths have been cut using a diamond saw.

\section{Task 4.2 Evaluation of Commercial Catalysts for Power Plant Conditions}

The objective of this task is to evaluate SCR costs at a deeper level and to improve estimates of actual costs. One of the prime motivations for this program is to look at the influence of the alkali and alkaline earth elements in biomass and how those affect SCR catalyst when biomass is co-fired with coal.

Design of the multi-catalyst slipstream reactor was completed by the University of Utah during this quarter. Before beginning the detailed design, a decision was made to carry out the testing at full-scale power plants using a slipstream of gas instead of at the University of Utah pilot-scale coal combustor as originally planned. Since the scope of work for Task 4 was proposed and approved a significant amount of new information has come to light that impacts how we should proceed on this subtask. Conversations with EPRI, University of North Dakota EERC, Southern Company and catalyst manufacturers that have previously done slipstream testing of catalyst, as well as review of the more recent literature that was not available at the time of the original proposal has shown that a minimum of six weeks (1000 hours) is needed to see significant deactivation. Even longer time will be required to get the information on deactivation as a function of time that is needed for developing a kinetic mechanism. Thus the original idea of three months per coal mixture does not now appear to be adequate.

The flow system testing was to have been carried out at the University of Utah's large coal combustion facility (L1500). However, if the length of testing were extended in order to see significant deactivation, the cost of carrying out the tests would be greatly increased because of 
additional costs for fuel and operating labor. Therefore, it was decided that slipstream testing for six-month periods should be carried out at full-scale utility power plants in order to ensure that the cost is affordable and to obtain an even better representation of the flue gas than originally planned.

We plan to test at one plant that burns a coal containing a significant amount of alkali (western subbituminous such as a Powder River Basin coal or a lignite) and at one plant burning a coalbiomass blend. One utility (Allegheny Energy) has already expressed great interest in hosting a long-term test at one of their plants that co-fire wood with coal.

Deactivation of the catalysts will be measured in the laboratory under controlled conditions and in the field using CEMs. A section of the catalyst would be removed periodically and taken back to the KSR at BYU where the activity would be measured under well-controlled conditions. Discussions with catalyst vendors have suggested that it is critical to remove catalyst samples periodically from the flow reactor and test their activity under well-controlled laboratory conditions.

Field measurements of $\mathrm{NO}_{\mathrm{x}}$ will provide additional information on catalyst deactivation. There are two approaches to quantifying catalyst deactivation in the field from the slipstream reactor tests:

1. Periodic measurement of inlet/outlet $\mathrm{NO}_{\mathrm{x}}$

2. Long-term, continuous measurement of inlet/outlet $\mathrm{NO}_{\mathrm{x}}$

In Method 1, which has been used by other groups such as University of North Dakota EERC, inlet and outlet $\mathrm{NO}_{\mathrm{x}}$ are only measured at the time that the catalyst is removed from the field reactor, typically every 4-8 weeks. At that time a portable continuous emission monitor system is used to measure inlet and outlet $\mathrm{NO}_{\mathrm{x}}$ for a short period of time (typically for several hours), thus giving a snapshot of the activity in the field.

In Method 2, the inlet and outlet $\mathrm{NO}_{\mathrm{x}}$ are measured using a dedicated, continuous emission monitors throughout the entire duration of the test. The advantages of Method 2 are that one obtains a curve of deactivation as a function of time, which can be used to infer kinetic mechanisms, as well as activity data under more relevant conditions. Method 1, by contrast, only gives points (and infrequent ones at that) on the deactivation curve. The conditions in the slipstream flow reactor (temperature, $\mathrm{NO}_{\mathrm{x}}$, water, etc.) will, in all likelihood, not be constant, and it will be hard to correct the observed activity for all those changes. Added to that concern is the difficulty of getting accurate and reliable inlet and outlet $\mathrm{NO}_{\mathrm{x}}$ measurements for several months.

We had planned originally for only on-line measurement of $\mathrm{NO}_{\mathrm{x}}, \mathrm{SO}_{2}$ and ammonia in the slipstream reactor testing using existing equipment at the University of Utah. However, moving the reactor testing to a power plant slipstream increases the cost of making continuous measurements of gas composition. More rugged, field-ready equipment (particularly instrumentation capable of unattended operation for long periods of time) would have to be purchased or leased. 
On-line continuous measurement of $\mathrm{NO}_{\mathrm{x}}$ at the inlet and outlet of the flow reactor (Method 2) would provide unprecedented information on catalyst activity as a function of time, which would provide a more detailed description of deactivation and would serve to enhance the laboratory measurements of activity. In order to achieve six months of testing at each of two power plants, as we have proposed here, on-line measurement of $\mathrm{NO}_{\mathrm{x}}$ would be an added expense that would preclude long-term testing with different fuels. The applicability of the deactivation model will almost certainly be greater if two different fuels (low rank and coal-biomass blend) can be tested. Thus, long-duration on-line measurement of $\mathrm{NO}_{\mathrm{x}}$ will not be made on the multi-catalyst reactor unless sufficient additional funds are secured.

Design of the slipstream reactor was completed during this quarter, including the specific hardware needed for deployment at Allegheny Energy's Albright Station. Figure 4.1.4-3 shows a schematic of the multi-catalyst reactor. The reactor will be attached to boiler at the economizer outlet (where approximately $250 \mathrm{scfm}$ of gases will be withdrawn through a probe inserted in an existing port) and at the air heater exit (where the gases will be exhausted through an existing port after passing through the reactor). The reactor itself is approximately 8 feet long, with a 25 x 30 inch footprint, and weighs approximately $500 \mathrm{lbs}$. The reactor will be well insulated and securely fastened

The reactor will draw boiler gases through a four-inch, $150 \mathrm{lb}$ steel flange with a 48 " piece of 3 inch schedule $40 \mathrm{SS}$ pipe welded to it will be mounted on the existing port's flange. The pipe will be inserted into the duct through the flange; this will also be called the boiler suction tube because its function is to withdraw a sample from the gas in the duct. The pipe will be welded to a 6" $150 \mathrm{lb}$ flange right after passing through the 4" flange. A 6" knife valve will be bolted on next; the valve housing is 30 " long. Anhydrous ammonia will be introduced into the slipstream just downstream of the knife valve. A 6" ID elbow turns downward and is connected to flexible 6-inch "chimney pipe" that changes from round to rectangular to enter the catalyst housing. The housing is 20 " $\mathrm{x} 15$ " $\mathrm{x} 50$ "long. On the bottom of the catalyst housing is a bank of venturi flowmeters and eductors to draw the exhaust gases through the apparatus. From here the shell returns to 6"DD SS spiral-wound gas-tight pipe that extends to the next row of ports at the Air Preheater outlet in order to return the gases to the system. 


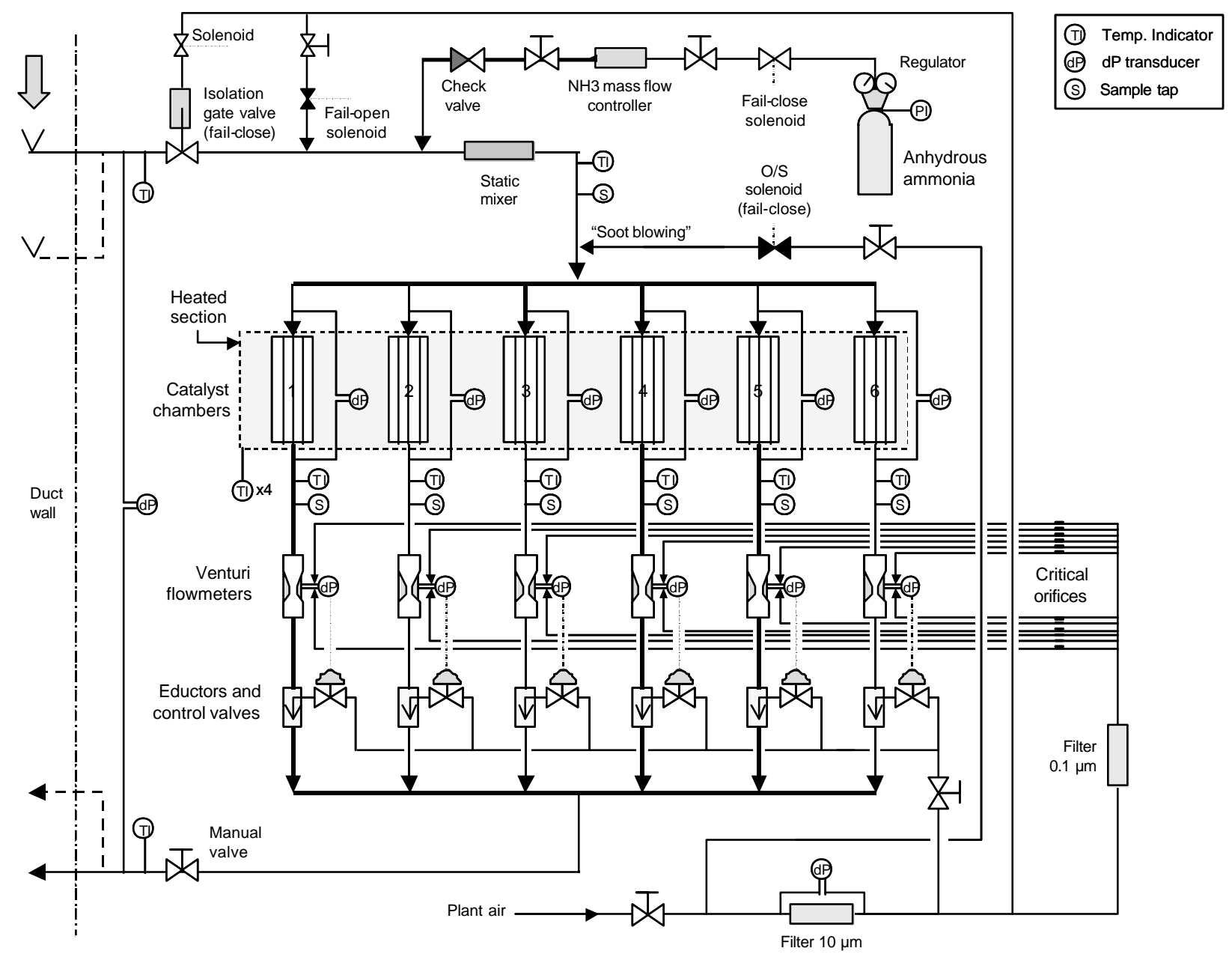

Figure 4.1.4-3. Schematic of Multi-catalyst Slipstream Reactor.

The reactor is designed to require as little operator intervention and maintenance as possible. Operation of the slipstream reactor will be monitored by REI via remote access of the control system using a dedicated phone line. REI will notify the plant of any major changes in status or operation of the reactor. REI may ask the plant to make minor modifications to the reactor as required. REI will arrange for delivery of ammonia tanks to the plant. Periodically the plant personnel will be required to change out ammonia tanks and see that empty tanks are removed.

Six catalysts will be tested, four monolith and two plate. Four commercial manufacturers agreed to provide samples to the program. During this quarter, Confidentiality Agreements were completed with all the catalyst vendors to allow them provide samples. Five of the catalysts to be tested will come from catalyst manufacturers. The sixth catalyst will be a generic vanadiatitania catalyst formulated at BYU.

The catalysts will be configured as shown in the Figure 4.1.4-4. The four monolith catalysts will be installed in four sections each. Each section will have a cross section of 2.25 by 2.25 inches, and will be housed in a 48 inch long aluminum square tube with outer dimensions of 2.5 by 2.5 inches and 1/8" wall thickness. The overall cross section of each monolith catalyst will be $4.5 \mathrm{x}$ 
4.5 inches. The four tubes will be bunched together as a square with outer dimensions $5.0 \times 5.0$ inches.

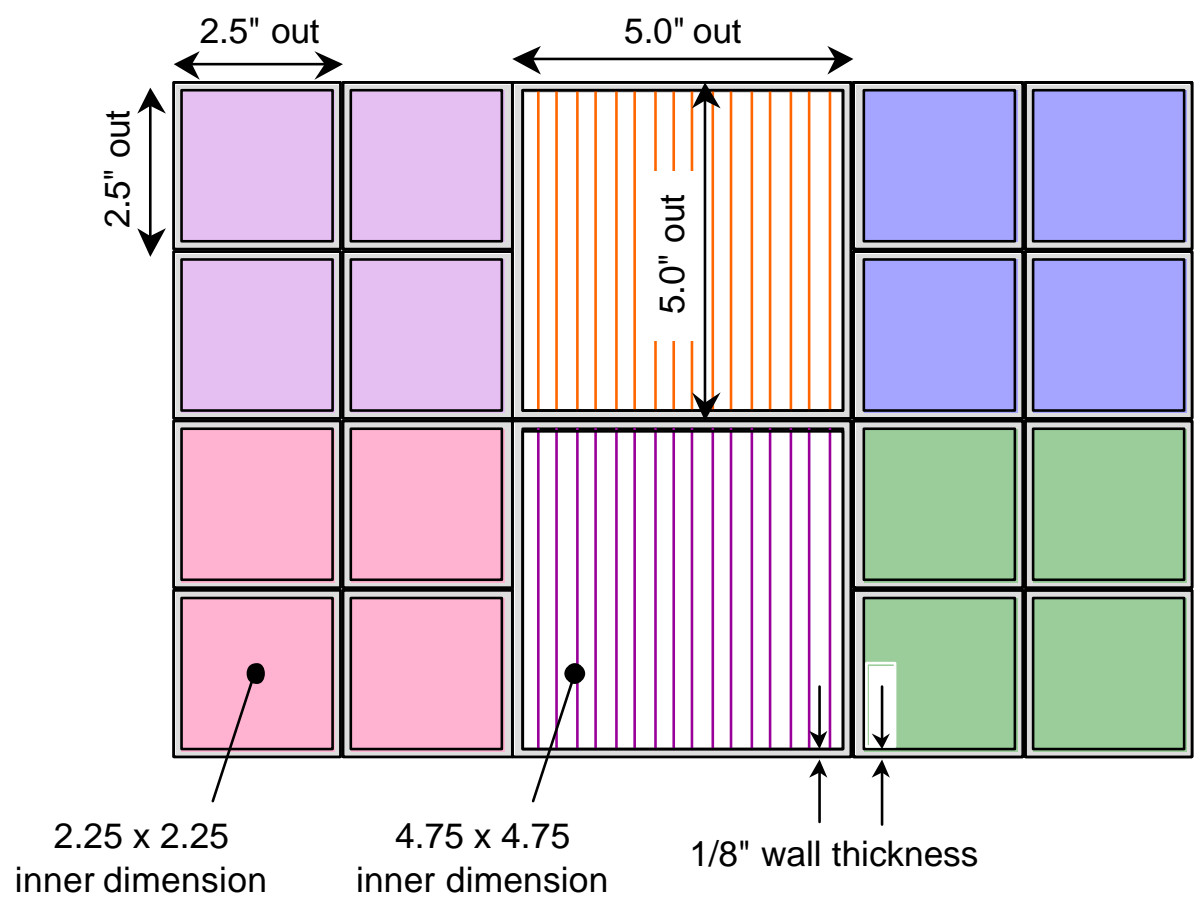

Figure 4.1.4-4. Catalyst Configuration in Multi-catalyst Reactor.

The plate catalysts will be housed in square aluminum tubes with an inside dimension of 4.75 inches (5.0 inches outside, 1/8" wall thickness). Roughly 20 plates will be placed in the tube, resting in slots along opposite walls. This configuration will have the same outer dimensions as the groupings of monolith catalysts. 


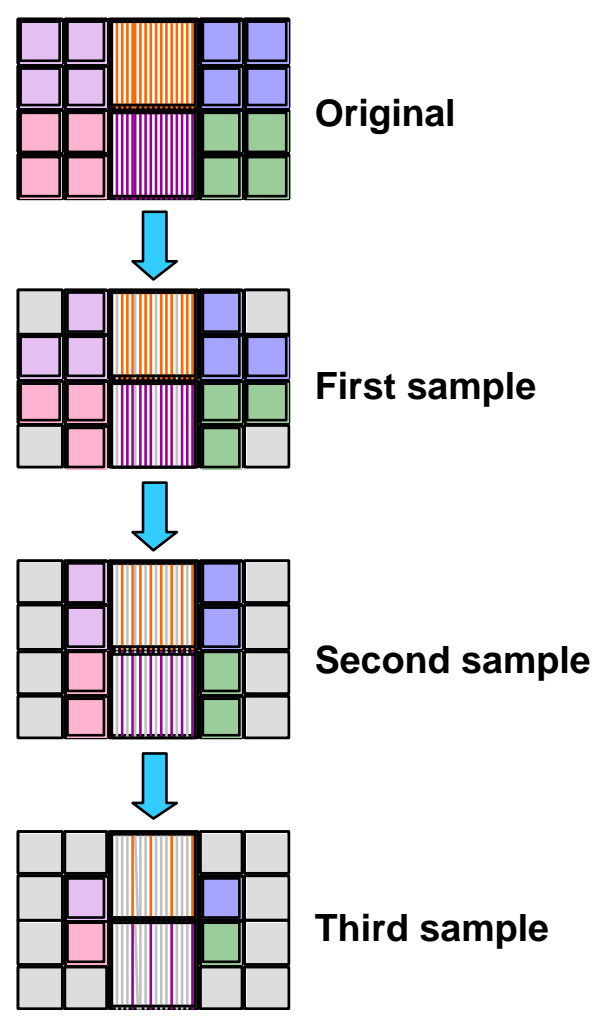

Figure 4.1.4-5. Catalyst Sampling Scheme
Catalyst samples will be taken three times during the testing period in order to diagnose deactivation.

Samples of monolith catalyst will be taken by removing one of the four chambers entirely. The opening that remains will be blocked off at the inlet by a sloped cover to minimize ash deposition and flow disturbances.

Plate catalyst samples will be taken by removing every fourth plate, and replacing it with a non-reactive dummy plate.

The order of catalyst removal is shown in Figure 4.1.4-5. Blocked monolith chambers are shown by a gray square. Non-reactive dummy plates are shown in gray. Monolith chambers are removed starting from the outside in order to keep the profile as centered and uniform as possible.

The open cross section of the catalyst system decreases as samples are removed. To keep the flow velocity constant through the chambers, the overall flow through the system is decreased correspondingly as catalysts are removed, as described above in the section on the flow control system. In terms of the initial flow through the system, the overall flow follows the progression $100 \%$, $83 \%, 67 \%, 50 \%$. The pressure drops across the six catalyst sections (divided by catalyst type) are adjusted so that they are identical to each other. Thus, the flow velocity per catalyst chamber should be the same throughout the duration of the tests.

\section{Task 4.3 Evaluation of Catalyst Regeneration}

The focus of this sub-task is to evaluate the effectiveness of commercially viable catalyst regeneration techniques. Regeneration of catalysts used in Subtask 2 will be investigated at BYU using water and solvent washing techniques. At a minimum, two regeneration techniques will be used: water and sulfuric acid washing. Additional regeneration techniques may be attempted, depending on the success of these two. Catalyst activity before and after each rinsing will be reported.

Within the last performance period, mechanisms of catalyst reactivation have been explored based on both literature results and experience of other, mostly European, institutions. Several promising reactivation mechanisms have been established. However, serious investigation of these will await the results of the deactivation mechanisms within this project. 


\section{Task 5 - Fly Ash Management/Disposal}

This task deals with the undesirable adsorption of ammonia on fly ash associated with the operation of advanced NOx control technologies such as selective catalytic reduction. The task examines the fundamentals of the adsorption process as well as the fundamental process underlying potential techniques for post-combustion removal of adsorbed ammonia. This task is being performed at Brown University under the leadership of Professors Bob Hurt and Eric Suuberg. The previous (Fifth) Progress Report focused on Task 5.2- Ammonia Removal. During the present reporting period, attention was once again mainly directed at Task 5.1- Ammonia Adsorption Mechanisms.

\section{Task 5.1 Ammonia Adsorption Mechanisms}

In the Fourth Progress Report, it was concluded that significant amounts of pure ammonia adsorption could take place on the surfaces of fly ash, and that the unburned carbon in the ash dominated this adsorption process. That work was primarily performed at $0^{\circ} \mathrm{C}$. It had also earlier been concluded that pure ammonia adsorption could not explain the high ammonia uptakes obtained in actual field samples or in laboratory samples produced in simulated flue gas environments. There was a concern that the temperatures of the earlier experiments might have been one contributing factor in the observed low uptakes. During this period, pure ammonia adsorption was therefore studied over a wider range of temperatures.

The experimental procedures employed for characterizing ammonia uptake have been described in previous progress reports. Briefly, the technique involves exposing a sample of fly ash to a precisely measured pressure of pure ammonia, while maintaining system temperature constant. The equipment used for this purpose was an Autosorb-1 device from Quantachrome Corporation. This device measures the uptake of adsorbate (ammonia) on a sample from a pressure change calculated between the time of sample dosing and final equilibration. The physisorption experiments described below were carried out using either an ice bath (at $0^{\circ} \mathrm{C}$ ) or a circulating water bath (at around $32^{\circ} \mathrm{C}$ ). The chemisorption experiments were carried out using a furnace to maintain a constant $150^{\circ} \mathrm{C}$ sample temperature. The procedure was otherwise similar. In most cases, samples were outgassed in vacuum at $300^{\circ} \mathrm{C}$, prior to conducting the experiments.

Figure 4.1.5.1 shows the uptakes of ammonia on a typical class $\mathrm{C}$ fly ash that was produced in a utility boiler from Powder River Basin subbituminous coal. The results are plotted in the customary adsorption isotherm form of uptake as a function of relative pressure, where Po represents the saturation pressure of ammonia at the particular temperature of the experiment. The results show that the uptake of ammonia is independent of temperature in the range from $0^{\circ} \mathrm{C}$ to $32^{\circ} \mathrm{C}$. This is characteristic of physisorption processes with an enthalpy of adsorption that is reasonably close to the enthalpy of condensation of the pure (ammonia) vapor. Consequently, the observed process again reveals itself to be simple physisorption.

The uptake of ammonia on a sample of the same fly ash in which all of the carbon was burned out is also shown in Figure 4.1.5.1 for reference. Despite the fact that the original ash has only a 1.3\% LOI content, comparison of the results in Figure 4.1.5.1 confirms that it is adsorption onto the carbon that is responsible for the greatest amount of uptake (at least at high relative pressures). 


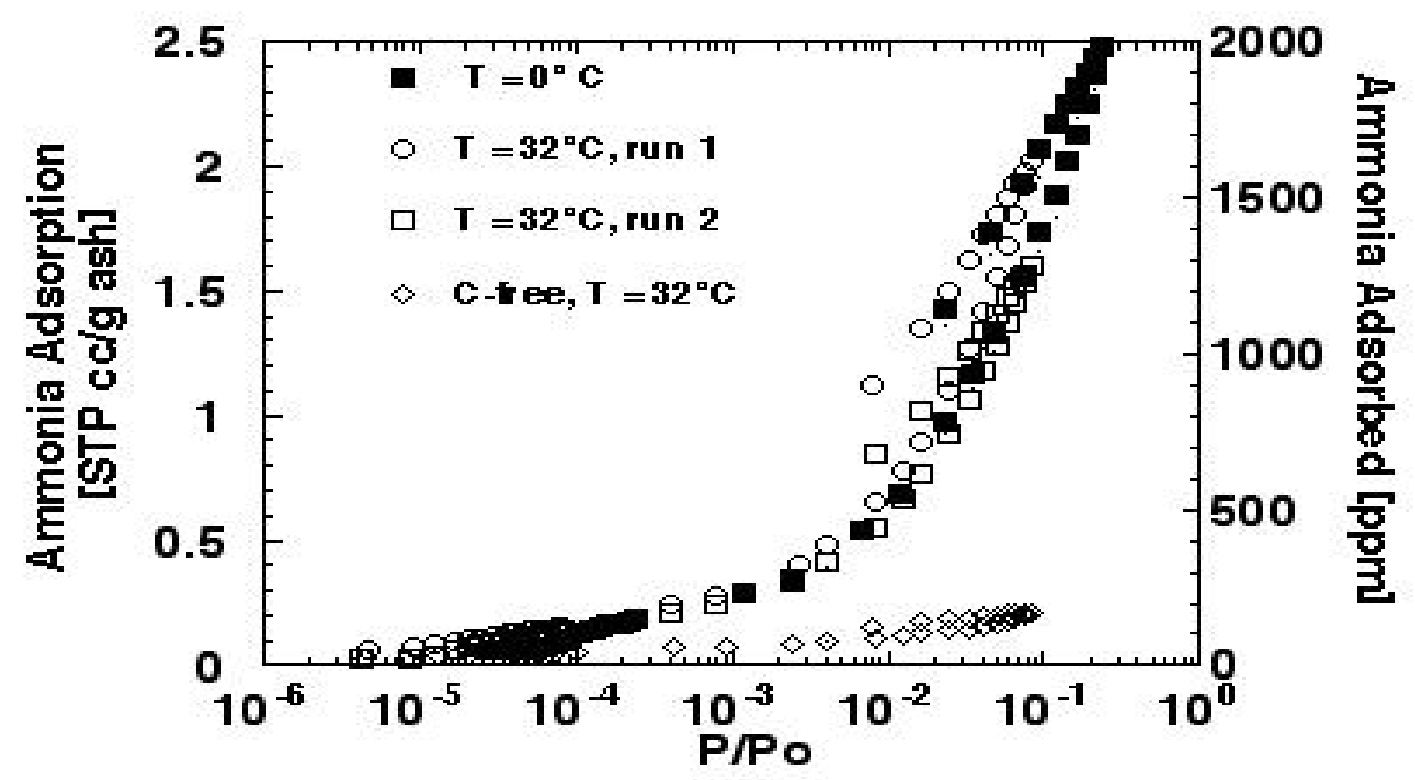

Figure 4.1.5.1 Ammonia adsorption isotherms on a fly ash produced from Powder River Basin subbituminous coal. The carbon-free sample was prepared in a laboratory oven by burning out the carbon from the as-received $1.3 \%$ LOI sample.

As far as typical ammonia slip conditions are concerned, it is only the very low relative pressure range of Figure 4.1.5.1 that is of any relevance. This portion of the graph is shown separately as Figure 4.1.5.2. In Figure 4.1.5.2, a relative pressure of $10^{-5}$ corresponds to an equivalent atmospheric pressure ammonia concentration of about $40 \mathrm{ppm}$ at $0^{\circ} \mathrm{C}$ and $120 \mathrm{ppm}$ at $32^{\circ} \mathrm{C}$. Again, the difference arises from the fact that the saturation pressure Po is a function of temperature. 


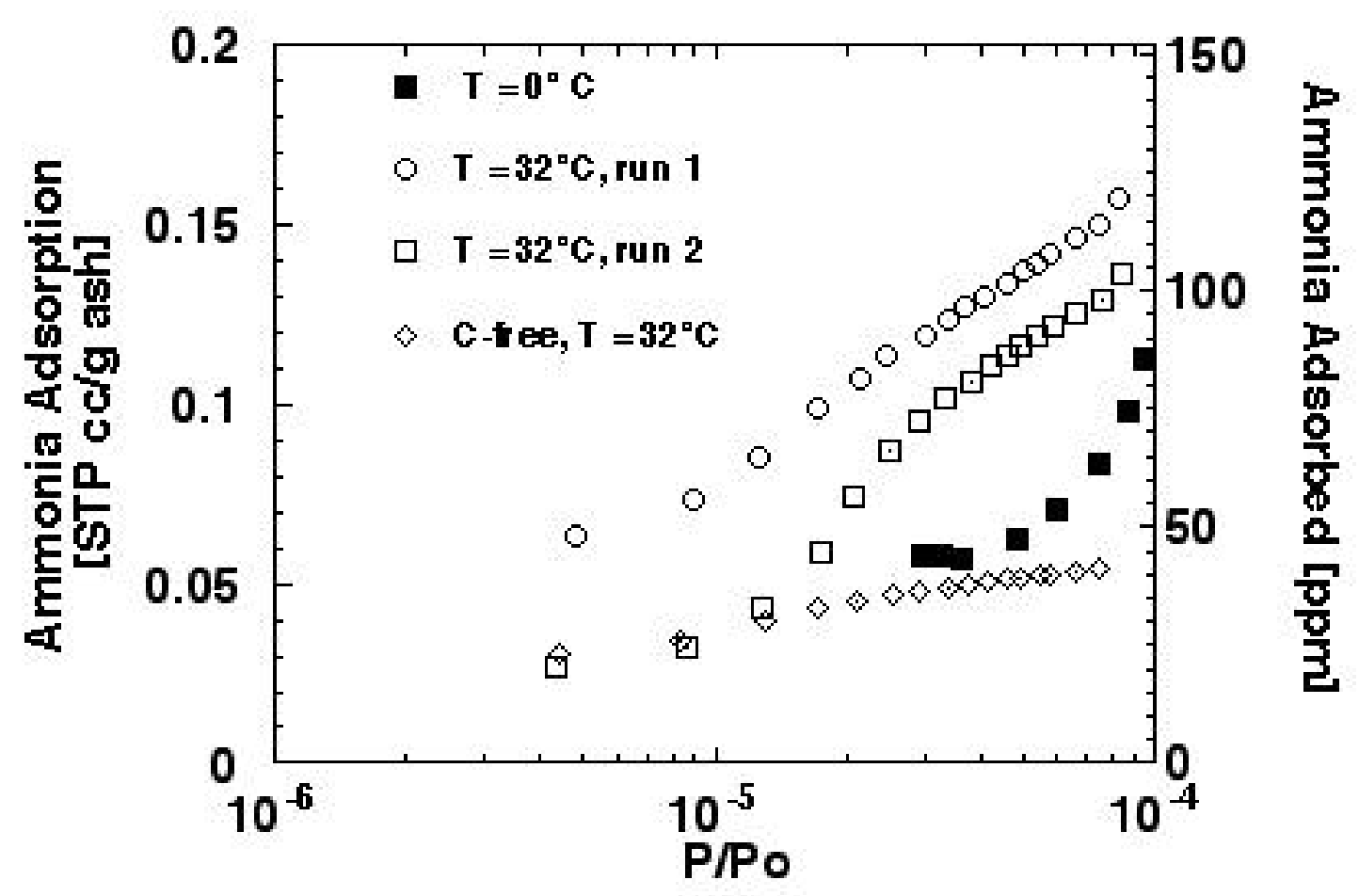

Figure 4.1.5.2. The data of Figure 4.1.5.1 re-plotted to emphasize the low ammonia partial pressure range.

Figure 4.1.5.2 suggests that at low pressures, it is the contribution of the minerals (the noncarbon inorganic fraction) which dominates the adsorption process. The actual amount of adsorption is fairly modest in the normal ammonia slip range of concentrations- for all of these samples, the uptake would be no more than some tens of ppm ammonia by weight, as compared to the typical hundreds of parts per million in many commercial ashes. As already discussed in the Fourth Progress Report, it is believed that the higher observed uptakes in the commercial ashes have to do with the important roles of $\mathrm{SO}_{2}$ and moisture which are present in the real systems.

One further feature that may be noted from Figure 4.1.5.2 is that there is a small difference in the $32^{\circ} \mathrm{C}$ isotherms in this low pressure range (as distinct from the excellent agreement observed in Figure 4.1.5.1, in the higher relative pressure range). Such variability in the low-pressure range has been observed to be quite common in our work, and this apparently has to do with small differences in the extents of sample surface oxidation. As already noted in the Fourth Progress Report, it is oxidation (or ozonation) that strongly influences the magnitude of the uptake at very low ammonia pressures. This is apparently associated with the interaction of ammonia with oxide functionalities on the surface. 


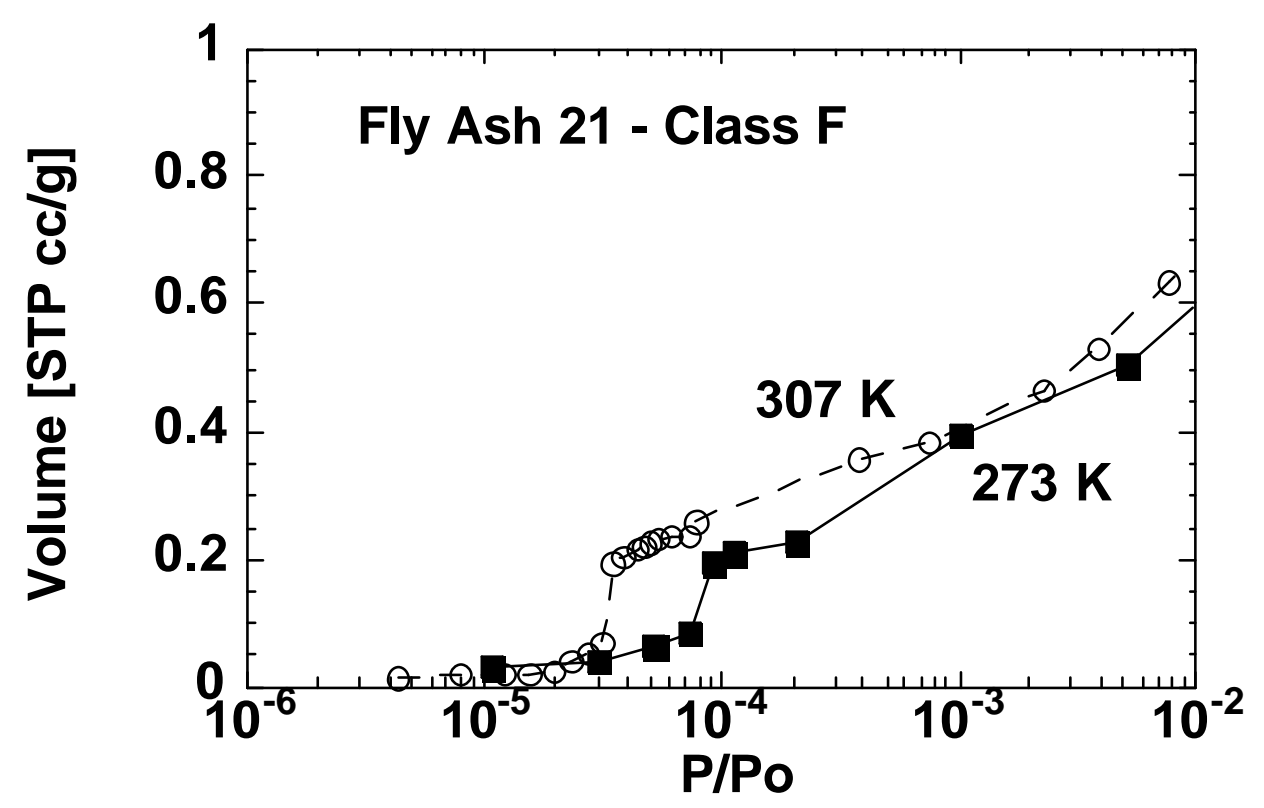

Figure 4.1.5.3. The temperature dependence of pure ammonia adsorption on a class $\mathrm{F}$ fly ash (6.1 $\%$ LOI).

Figure 4.1.5.3 shows a comparison of two different isotherms $\left(0^{\circ} \mathrm{C}\right.$ and $\left.34^{\circ} \mathrm{C}\right)$ obtained on a class $\mathrm{F}$ fly ash. As in the case of the class $\mathrm{C}$ ash, there is little difference in the higher relative pressure range. The difference that is observed at low relative pressures is an artifact of plotting the uptakes as a function of relative pressure- the value of Po is higher for the $34^{\circ} \mathrm{C}(307 \mathrm{~K})$ isotherm than for the $0^{\circ} \mathrm{C}(273 \mathrm{~K})$ isotherm. The sharp jump characteristic of oxidized surfaces is quite apparent at both temperatures, and is of comparable magnitude in both cases.

The critical temperature of ammonia is roughly $132^{\circ} \mathrm{C}$. Ordinary processes of physisorption, as dominate in the low temperature range shown in Figures 5.1 through 5.3 are, generally speaking, no longer possible above the critical temperature, as there is no longer a driving force for formation of a condensed phase of ammonia. This does not, however, preclude the possibility of strong interactions of ammonia with the substrate, as will be seen below. 
In order to explore the processes of adsorption at temperatures more like those involved in adsorption from flue gases, the Autosorb-1 equipment was used in a slightly different manner than it was for the ordinary physisorption experiments. For these experiments, a furnace was substituted for the usual water bath used for maintaining a constant sample temperature. The experimental procedure was otherwise identical. Data obtained from chemisorption experiments such as these are generally not plotted as a function of relative pressure, since the normalization with respect to an ordinary condensed phase saturation pressure does not make sense above the critical temperature. Figure 4.1.5.4 shows the results of these experiments.

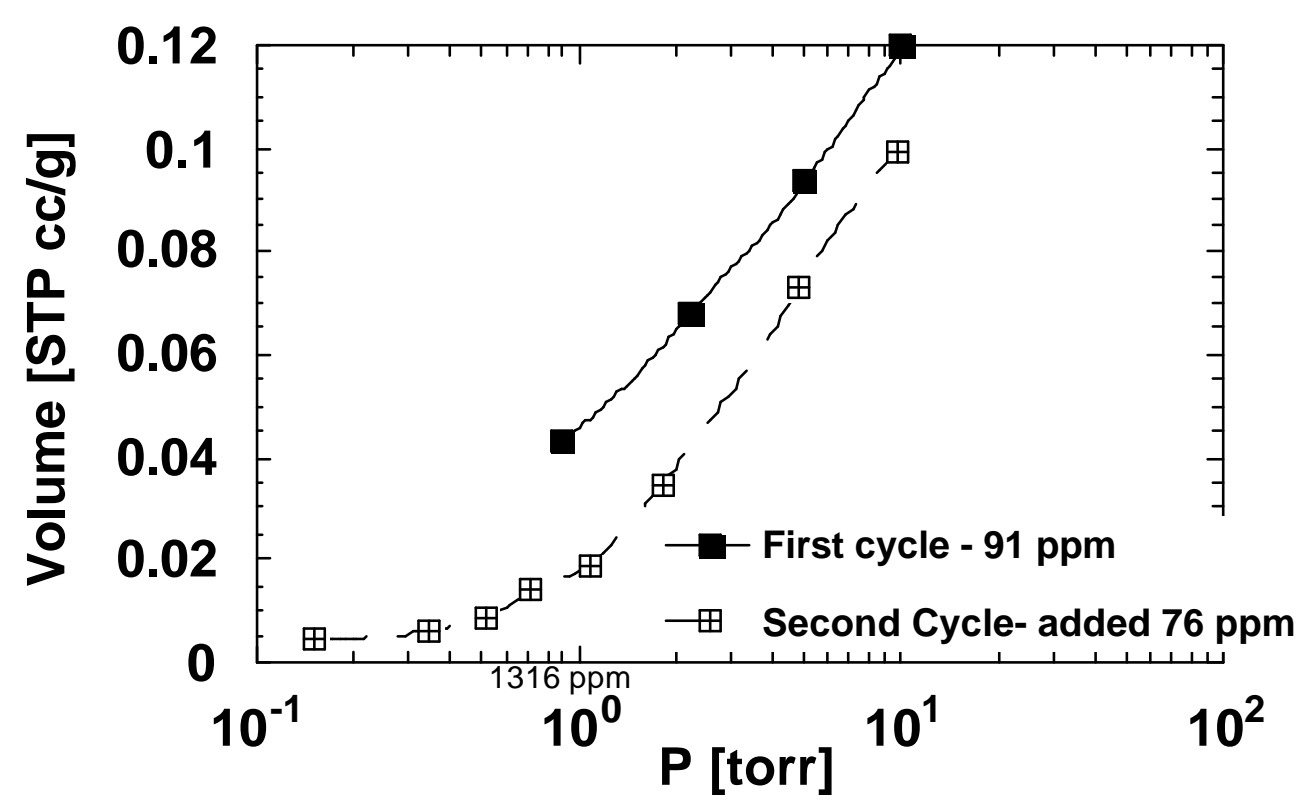

Figure 4.1.5.4. Ammonia adsorption on class F fly ash 21 , at $150^{\circ} \mathrm{C}$.

Figure 4.1.5.4 shows that there is indeed significant adsorption possible at temperatures above the critical temperature. As is noted on the abscissa, these data were still taken at a fairly high pressure of ammonia, compared to ordinary ammonia slip concentrations or pressures. The fact that there is even this much uptake at a temperature in excess of the critical temperature indicates that there are some strong interaction processes involved.

In Figure 4.1.5.4, the indicated ppm values of uptake refer to the maximum mass uptakes following the first and second cycles of ammonia adsorption, on the same sample. The sample was heated to $180^{\circ} \mathrm{C}$ for about an hour in between these two cycles. The fact that the curve for the second cycle was below that for the first implies that there was some irreversible adsorption taking place during the first cycle. 


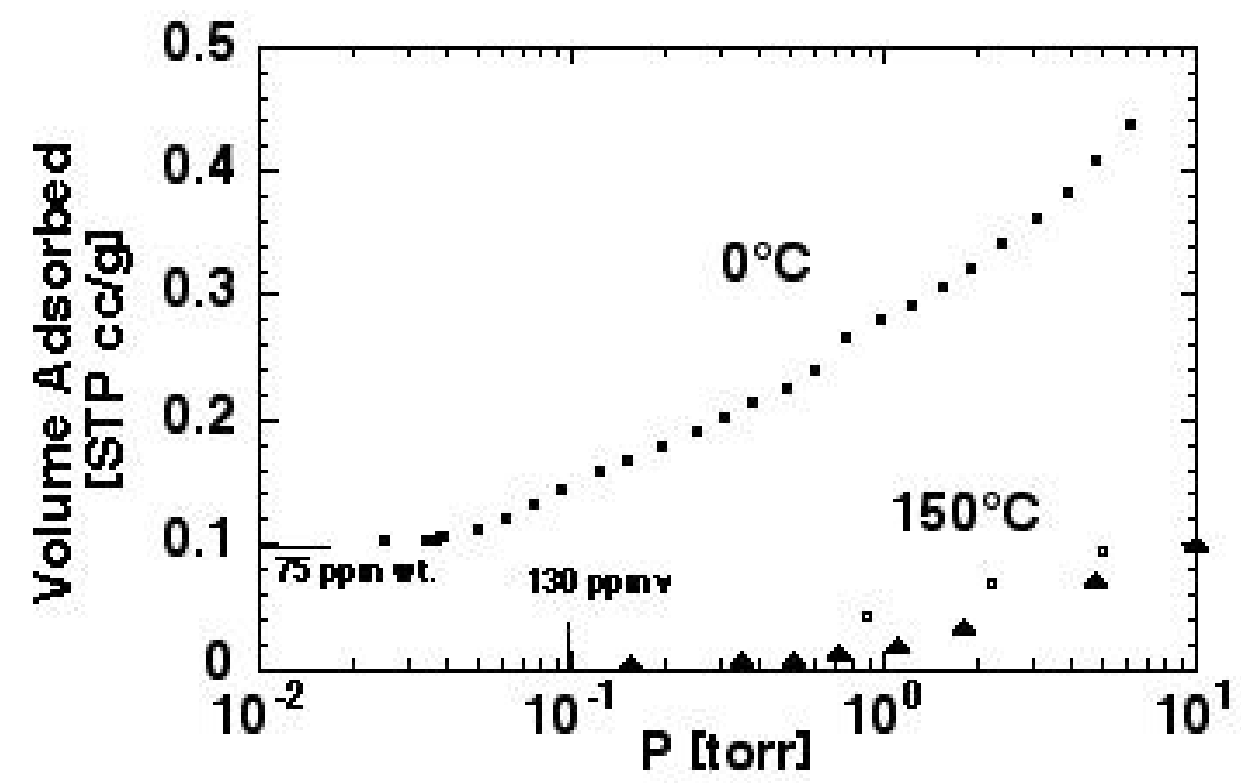

Figure 4.1.5.5. A comparison of ammonia adsorption at temperatures above and below ammonia's critical temperature. Results are shown for fly ash 21 (6.1\% LOI).

Figure 4.1.5.5 shows a comparison of the ammonia uptake curves on a class $\mathrm{F}$ fly ash at temperatures below $\left(0^{\circ} \mathrm{C}\right)$ and above $\left(150^{\circ} \mathrm{C}\right)$ the critical temperature for ammonia. It is very clear that these results support the central role that simple physisorption plays in pure ammonia uptake at the low temperature conditions. The results also leave little doubt that processes involving pure ammonia adsorption cannot play any significant role in fixing ammonia to the fly ash under "normal" ammonia slip conditions. Not even the processes involving only the inorganic components, as dominated the very low ammonia partial pressure range in simple physisorption, contributes any significant uptake at these higher temperatures.

As a result of these experiments, it becomes clearer that other flue gas components, and in particular $\mathrm{SO}_{2}$, must play a key role in fixing ammonia to the ash under practical conditions. This is consistent with the hypothesized role of these species, already reviewed in the Fourth Progress Report. Thus the strategies for control of the ammonia problem must be designed taking this into account. 


\section{Task 6 - Field Validation of Integrated Systems}

\section{Field Tests}

The second series of field tests of RRI at Ameren's Sioux Unit 1 have been re-scheduled to late Spring, 2002. These tests were originally scheduled to be completed in late Fall, 2001. Sioux Unit 1 is a 480 MW opposed wall fired cyclone unit located south of St. Louis MO. The process design was based on previously completed CFD based modeling conducted by REI and includes a total of 20 wall injectors in three elevations between the cyclone barrels and OFA ports. This is the largest boiler for which REI has created a RRI process design. The RRI field test at Sioux Unit 1 was originally intended to be only a short duration field test during the summer/fall time period. Hence, the auxiliary equipment needed to provide the urea to the boiler is not equipped with heaters, etc such as would be required to perform the tests during cold weather. At present, the schedule calls to resume testing in Spring, 2002. It should be noted that EPRI and Ameren are covering the costs for this field test. No DOE funds are being used to conduct the tests. 


\section{Results and Discussion}

RRI: The second series of field tests of RRI at the Ameren Sioux Unit 1 have been rescheduled until Spring, 2002 due to cold weather conditions affecting the operability of the test rig and auxiliary equipment.

Corrosion Probe: Analysis of results of a study on the application of a real-time electrochemical noise $(\mathrm{ECN})$ corrosion probe in the radiant section of a utility boiler is nearly completed. The purpose of the field tests was to demonstrate that corrosion in a full-scale plant could be accurately measured in real-time and waterwall wastage could be determined immediately following changes in boiler operation. Specifically it was intended to study the performance of the ECN probe in the high-temperature waterwall area of a pulverized-coal-fired boiler. Of major concern was the integrity of the hardware in such a severe environment. The field test results showed that corrosion rate was strongly linked to the boiler load. The higher the boiler load, the higher the corrosion rate. A good correlation between corrosion rate and heat flux was also demonstrated. The performance of the probe in the boiler has settled some unresolved technical issues including the ability to operate in a particulate laden environment and to maintain it's integrity in the harsh lower furnace environment. This demonstration has confirmed that on-line electrochemical noise sensors can be used to assess high-temperature corrosion in the radiant section of a coal-fired utility boiler. Because only two boiler elevations were used in the boiler field tests, during the last performance period complimentary laboratory experiments were conducted to augment data for comparison between profilometric measurements and electrochemical noise corrosion rates. The laboratory results showed that stoichiometry, flue gas concentration $\left(\mathrm{H}_{2} \mathrm{~S}\right.$ and $\left.\mathrm{HCl}\right)$ and probe operating temperature all affected the measured corrosion rate. As the stoichiometric ratio was reduced, the concentration of acid gases increased and the probe sensor temperature increased, the measured corrosion rate also increased. Difficulties with a steady coal feed in the laboratory furnace precluded extensive testing. A generalized plot of corrosion rates obtained from laboratory tests and fieldwork shows a good correlation between profilometric measurements and electrochemical noise corrosion rates.

SCR Catalyst: Six SCR catalysts, four monolith and two plate, will be tested under Task 4. Four commercial manufacturers of catalysts have agreed to provide samples to the program. During this quarter, Confidentiality Agreements were completed with all the catalyst vendors to allow them provide the catalyst samples. Five of the catalysts to be tested will come from catalyst manufacturers. The sixth catalyst will be a generic vanadia-titania catalyst formulated at BYU. During this quarter, BYU prepared two V/Ti oxide catalysts (custom, powder form) containing commercially relevant concentrations of $\mathrm{V}$ oxide and one containing a $\mathrm{W}$ oxide promoter. Two separate pieces of experimental apparatus are being built at BYU to carry out laboratory-scale investigations of SCR catalyst deactivation: the kinetic flow reactor (KSR) and the in-situ spectroscopy reactor (ISR). Experiments in the KSR will focus on obtaining the kinetic coefficients and mechanistic information. Deactivation will be determined by measuring specific intrinsic activity of custom and commercial catalysts impregnated to different contaminant levels. The first gas flow through the reactor is scheduled for end of January. The ISR is designed to quantify species adsorbed on surfaces during reaction and provide quantitative indication of acidity and active site mechanisms. The ISR relies on FTIR analyses of $\mathrm{SO}_{2}, \mathrm{NH}_{3}$, 
and $\mathrm{NO}_{\mathrm{X}}$ adsorption and desorption to elucidate the behavior of fresh and exposed catalysts. Construction of the ISR is nominally complete and initial data have been collected. Both pieces of equipment are nearly completed. Design of the multi-catalyst slipstream reactor was completed by the University of Utah during this quarter. Before beginning the detailed design, a decision was made to carry out the testing at full-scale power plants using a slipstream of gas instead of at the University of Utah pilot-scale coal combustor as originally planned. One utility (Allegheny Energy) has already expressed great interest in hosting a long-term test at one of their plants that co-fire wood with coal. Catalyst samples will be taken three times during the testing period in order to diagnose deactivation. Samples of monolith catalyst will be taken by removing one of the four chambers entirely; the flow will be adjusted accordingly. The opening that remains will be blocked off at the inlet by a sloped cover to minimize ash deposition and flow disturbances.

Fly Ash Management: The present quarter's experimental program has focused on the mechanisms of ammonia adsorption. The main issue that was explored was whether pure ammonia adsorption could make a significant contribution to ammonia uptake under practical ammonia slip conditions. It had been earlier concluded that low temperature adsorption of pure ammonia could result in large uptakes only at unrealistically high ammonia concentrations. The question that remained unresolved was whether there were any kinetically-limited routes for fixing ammonia that were available at higher temperatures. The present results have conclusively demonstrated that there were not. Raising the temperature of the adsorption experiments to above the ammonia critical temperature resulted in a sharp decline in the amount of pure ammonia adsorption. Thus all of the results in hand point strongly in the direction of the predominant role of co-adsorption, most likely involving $\mathrm{SO}_{2}$. 


\section{6}

\section{Conclusions}

Good progress has been made on several fronts during the last three months. In particular:

$>$ Licensing agreements have been completed with the Electric Power Research Institute (EPRI) and Fuel Tech, Inc. for Rich Reagent Injection (RRI) technology.

> Laboratory tests to evaluate a corrosion probe to predict waterwall wastage in utility boilers have been completed. Analysis of the data for field tests performed at the FirstEnergy Eastlake Power Station is still in progress. Preliminary results indicate good agreement between the electrochemical noise corrosion rates predicted by the probe and corrosion rates measured by a surface profilometer as part of the field and laboratory tests. The Eastlake station tests were the first demonstration of real-time high-temperature corrosion assessment in the radiant section of a coal-fired boiler.

Four commercial manufacturers agreed to provide samples to the program. BYU has prepared two $\mathrm{V} / \mathrm{Ti}$ oxide catalysts (custom, powder form) containing commercially relevant concentrations of $\mathrm{V}$ oxide and one containing a $\mathrm{W}$ oxide promoter. A total of six SCR catalysts will be tested under Task 4, four monolith and two plate. Confidentiality Agreements were completed with all the catalyst vendors to allow them provide samples. Two pieces of experimental equipment being built at BYU to carry out laboratory-scale investigations of SCR catalyst deactivation are nearly completed: a kinetic flow reactor (KSR) and an in-situ spectroscopy reactor (ISR). A decision was made to carry out the testing at full-scale power plants using a slipstream of gas instead of at the University of Utah pilot-scale coal combustor as originally planned. Design of the multi-catalyst slipstream reactor was completed by the University of Utah during this quarter. One utility has expressed interest in hosting a long-term test at one of their plants that co-fires wood with coal.

$>$ In the area of fly ash management, it has now been clearly established that the only routes that can play a role in binding significant amounts of ammonia to the ash surface, under practical ammonia slip conditions, are those that must involve co-adsorbates. The role of $\mathrm{SO}_{2}$ has been hypothesized to be particularly significant.

Plans for the next quarter include: further CFD analysis of the RRI design for Sioux Unit 1; completion of all data analysis for the laboratory and field tests conducted with the corrosion probe; completion of the laboratory equipment being developed at BYU for catalyst evaluation and completion and shake-down testing of the reactor to be used in field testing of catalysts; and with respect to fly ash management, work during the next reporting period is aimed at elucidating which particular species act by what mechanisms, with the experimental program turning towards carefully controlled co-adsorption characterization. 


\section{Literature References}

Adams, B., Cremer, M., and Wang, D., "Use of CFD Modeling to Evaluate NOx Reduction Technologies in Utility Boilers," Proceedings of POWER-GEN International Conference, Las Vegas NV, Dec 11-13, 2001.

Davis, C.J., James, P.J., Pinder, L.W. and Mehta, A.K., "Furnace Wall Fireside Corrosion in PFFired Boilers: The Riddle Resolved," presented at United Engineering Foundation Conference on Effects of Coal Quality on Power Plant Management: Ash Problems, Management and Solutions, Park City, Utah, May 2000.

Harb, J.N. and Smith, E.E., "Fireside Corrosion in PC-Fired Boilers," Prog.Energy Combust.Sci. 16, 169-190 (1990).

Linjewile, T.M., Davis, K.A., Green, G.C., Cox, W.M., Carr, R.N., Harding, N.S. and Overacker. D., "On-Line Technique for Corrosion Characterization in Utility Boilers". Presented at the Engineering Foundation Conference on Power Production in the $21^{\text {st }}$ Century: Impacts of Fuel Quality and Operations. Snowbird, Utah, November 28-December 2, 2001.

Stultz, S.C and Kitto, J.B, (Eds)., "Steam: Its Generation and Use," $40^{\text {th }}$ ediditon, Babcock and Wilcox Company, a McDermott company. p 40-12, (1992). 


\section{Appendix 1}

\begin{tabular}{|r|c|c|}
\hline \multicolumn{1}{|c|}{ UNIT } & Ch & Device \\
\hline \multicolumn{3}{|c|}{ Analog Input } \\
\hline FP-AI-110, 8 channel isolated input \\
\hline$\# 1$ & 1 & MFC - 1 \\
\hline & 2 & MFC - 2 \\
\hline & 3 & MFC - 3 \\
\hline & 4 & MFC - 4 \\
\hline & 5 & MFC - 5 \\
\hline & 6 & MFC - 6 \\
\hline & 7 & MFC - 7 \\
\hline & 8 & MFC - 8 \\
\hline
\end{tabular}

\begin{tabular}{|r|c|c|}
\hline \multicolumn{1}{|c|}{ UNIT } & Ch & Device \\
\hline \multicolumn{3}{|c|}{ Analog Output } \\
\hline FP-AO-210, 8 Channel analog output \\
\hline$\# 1$ & 1 & MFC - 1 \\
\hline & 2 & MFC - 2 \\
\hline & 3 & MFC - 3 \\
\hline & 4 & MFC - 4 \\
\hline & 5 & MFC - 5 \\
\hline & 6 & MFC - 6 \\
\hline & 7 & MFC - 7 \\
\hline & 8 & MFC - 8 \\
\hline
\end{tabular}

\begin{tabular}{|r|c|c|}
\hline \multicolumn{1}{|c|}{ UNIT } & Ch & Device \\
\hline \multicolumn{3}{|c|}{ Relay } \\
\hline FP-RLY-420, 8 SPST relays (250V @ 3A) \\
\hline$\# 1$ & 1 & 2-way Solenoid 1 \\
\hline & 2 & 2-way Solenoid 2 \\
\hline & 3 & 2-way Solenoid 3 \\
\hline & 4 & 2-way Solenoid 4 \\
\hline & 5 & 2-way Solenoid 5 \\
\hline & 6 & 2-way Solenoid 6 \\
\hline & 7 & 2-way Solenoid 7 \\
\hline & 8 & 2-way Solenoid 8 \\
\hline
\end{tabular}

\begin{tabular}{|r|c|c|}
\hline UNIT & Ch & Device \\
\hline \multicolumn{3}{|c|}{ Thermocouple Input } \\
\hline FP-TC-120, 8 Channel TC input X3 \\
\hline$\# 1$ & $1-8$ & All for 24 \\
\hline$\# 2$ & $1-8$ & Thermocouples \\
\hline$\# 3$ & $1-8$ & \\
\hline
\end{tabular}

**these use TB- 3 base

\begin{tabular}{|l|c|c|}
\hline$\# 2$ & 1 & MFC - 9 \\
\hline & 2 & MFC - 10 \\
\hline & 3 & MFC - 11 \\
\hline & 4 & MFC - 12 \\
\hline & 5 & MFC - 13 \\
\hline & 6 & MFC - 14 \\
\hline & 7 & $\begin{array}{c}\text { NH3/SO2 } \\
\text { Analyser }\end{array}$ \\
\hline & 8 & $\begin{array}{c}\text { NH3/SO2 } \\
\text { Analyser }\end{array}$ \\
\hline
\end{tabular}

\begin{tabular}{|l|l|l|}
\hline$\# 2$ & 1 & MFC - 9 \\
\hline & 2 & MFC - 10 \\
\hline & 3 & MFC - 11 \\
\hline & 4 & MFC - 12 \\
\hline & 5 & MFC - 13 \\
\hline & 6 & MFC - 14 \\
\hline & 7 & \\
\hline & 8 & \\
\hline
\end{tabular}

\begin{tabular}{|l|c|c|}
\hline$\# 2$ & 1 & 3-way Solenoid 1 \\
\hline & 2 & 3-way Solenoid 2 \\
\hline & 3 & 3-way Solenoid 3 \\
\hline & 4 & 3-way Solenoid 4 \\
\hline & 5 & 3-way Solenoid 5 \\
\hline & 6 & 3-way Solenoid 6 \\
\hline & 7 & 3-way Solenoid 7 \\
\hline & 8 & 3-way Solenoid 8 \\
\hline
\end{tabular}

\begin{tabular}{|r|c|c|}
\hline \multicolumn{3}{|c|}{ Digital Input (For Valve read) } \\
\hline FP-DI-330, 8 Channel Digital Input X1 \\
\hline$\# 1$ & 1 & 1 - black wire \\
\hline & 2 & 2 - brown wire \\
\hline & 3 & 4 - red wire \\
\hline & 4 & 8 - orange wire \\
\hline & 5 & 10 - yellow wire \\
\hline & 6 & \\
\hline & 7 & \\
\hline & 8 & \\
\hline
\end{tabular}

\begin{tabular}{|l|l|l|}
\hline$\# 3$ & 1 & Press Trans 1 \\
\hline & 2 & Press Trans 2 \\
\hline & 3 & Press Trans 3 \\
\hline & 4 & Press Trans 4 \\
\hline & 5 & Press Trans 5 \\
\hline & 6 & Nox Analyser \\
\hline & 7 & Nox Analyser \\
\hline & 8 & Nox Analyser \\
\hline
\end{tabular}

\begin{tabular}{|r|c|c|}
\hline \multicolumn{3}{|c|}{ For Multi-selector valve actuator (VALCO) } \\
\hline$\# 3$ & 1 & 1 - brown wire \\
\hline & 2 & 2 - red wire \\
\hline & 3 & 4 - orange wire \\
\hline & 4 & 8 - yellow wire \\
\hline & 5 & input enable - green wire \\
\hline & 6 & 10 - blue wire \\
\hline & 7 & home - violet wire \\
\hline & 8 & step - grey wire \\
\hline
\end{tabular}

Dual Channel I/O Module

FP-DO-DC60, Dual Channel Base

\begin{tabular}{|r|c|c|}
\hline card \# 1 & 1 & GC Switch 1 \\
\hline & 2 & GC Switch 1 \\
\hline card \# 2 & 1 & GC Switch 2 \\
\hline & 2 & GC Switch 2 \\
\hline
\end{tabular}

\begin{tabular}{|l|l|c|}
\hline$\# 4$ & 1 & Chromatograph \\
\hline & 2 & MFC - 15 \\
\hline & 3 & \\
\hline & 4 & \\
\hline & 5 & \\
\hline & 6 & \\
\hline & 7 & \\
\hline & 8 & \\
\hline
\end{tabular}




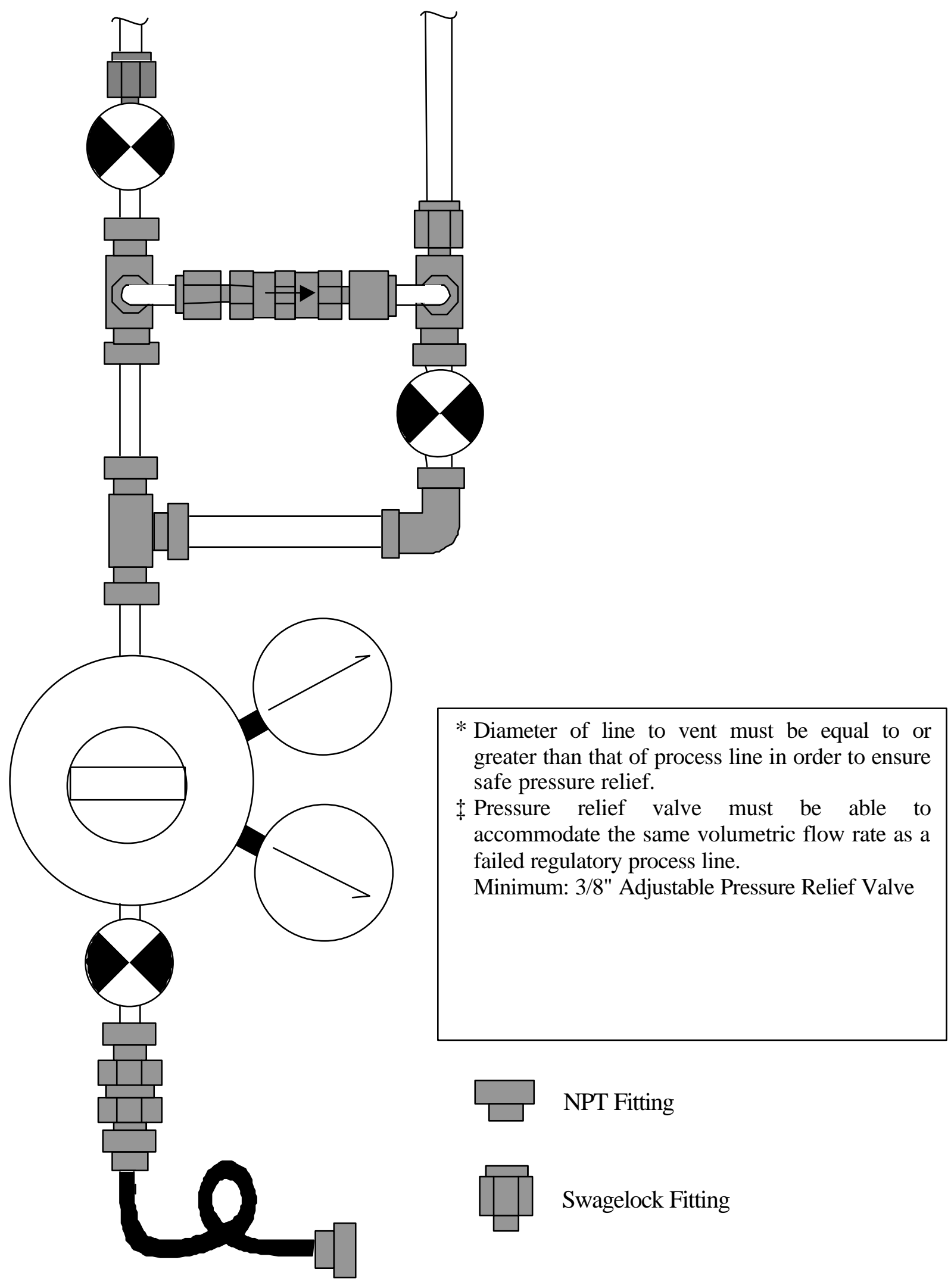

